\section{HLA-DR Human Histocompatibility Leukocyte Antigens-Restricted Lymphocyte-Monocyte Interactions in the Release from Monocytes of Acidic Isoferritins That Suppress Hematopoietic Progenitor Cells}

\author{
Hal E. Broxmeyer, Lisa Juliano, Li Lu, Erich Platzer, \\ and Bo Dupont \\ Departments of Developmental Hematopoiesis and Human \\ Immunogenetics, Memorial Sloan-Kettering Cancer Center, New \\ York 10021; Department of Medicine, Indiana University School \\ of Medicine, Indianapolis, Indiana 46223
}

bstract. Acidic isoferritins, which under normal conditions are released from monocytes and macrophages, have a suppressive effect in vitro on granulocytemacrophage, erythroid, and multipotential hematopoietic progenitor cells. Cell interactions modulating the release of acidic isoferritin-inhibitory activity (AIFIA) from human monocytes were investigated using the bone marrow granulocyte-macrophage progenitor cells as a target cell assay for assessing AIFIA. Monocytes, in the absence of T lymphocytes, released AIFIA when allowed to condition culture medium at $10^{4}$ or higher concentrations of monocytes/ml. However, subpopulations of $\mathrm{T}$ lymphocytes modulated the release of AIFIA from monocytes. OKT8 ${ }^{+}$and $\mathrm{OKT}_{4}^{+}-\mathrm{T}$ lymphocytes were obtained from E-rosettepositive lymphocytes by using $T$ lymphocyte subset-specific monoclonal antibodies in either a complement-dependent cytotoxicity test to select negatively for the cells or by selection using a "panning" procedure. OKT8 $8^{+} \mathrm{T}$ lymphocytes suppressed completely and OKT4 $4^{+} \mathrm{T}$ lymphocytes enhanced the constitutive release of AIFIA from monocytes. OKT4 ${ }^{+}$lymphocytes also induced the release

Dr. Broxmeyer is a scholar at the Leukemia Society of America, Inc. Dr. Lu is on leave from the Department of Medical Oncology, Cancer Institute and Cancer Hospital of Chinese Academy of Medical Sciences, Peking, China. Dr. Platzer is a visiting investigator from the Department of Immunology, University of Erlanden, Federal Republic of Germany. Address correspondence to Dr. Broxmeyer at Indiana University School of Medicine.

Received for publication 28 February 1983 and in revised form 6 December 1983.

J. Clin. Invest.

(c) The American Society for Clinical Investigation, Inc.

0021-9738/84/04/0939/15 $\$ 1.00$

Volume 73, April 1984, 939-953 of AIFIA from concentrations of $10^{3}$ monocytes $/ \mathrm{ml}$ which did not release measurable amounts of AIFIA by themselves. The release of AIFIA from monocytes involved HLA-DR ${ }^{+}$-monocytes and $-\mathrm{T}$ lymphocytes. Pulsing monocytes with monoclonal antibodies to framework determinants on HLA-DR molecules, in the absence of complement, did not influence the constitutive release of AIFIA. Pulsing monocytes or T lymphocyte subpopulations with such antibodies, in the absence of complement, blocked the suppressing and inducing activities of the appropriate subpopulations of T lymphocytes. Monoclonal antibodies to common determinants shared by HLA-A, B, and C molecules did not block these cellular interactions. Treating monocytes and $\mathrm{T}$ lymphocytes in a complement-dependent cytotoxicity test with dilutions of the anti-HLA-DR antibodies that did not block the cellular interactions removed the populations of monocytes constitutively releasing AIFIA and the T lymphocyte subsets modulating this release. Modulation of the release of AIFIA from monocytes by $T$ lymphocyte subpopulations required the use of autologous cells, cells from HLA-identical siblings, or unrelated donors matched for HLA-DR. Matching for only one HLA haplotype gave partial responses and this was seen in testing cells from related individuals as well as among unrelated test combinations. These cellular interactions were not detected with HLA-DR-incompatible cells differing for two HLADR antigens. Admixture of such HLA-DR-incompatible allogeneic cells did not interfere with the regulation of AIFIA release in the autologous cell interactions. Thus, release of AIFIA from monocytes is restricted genetically by HLA-DR at the level of T lymphocyte-monocyte interactions. The genetic determinants on the HLA-class II molecules that induce stimulation in vitro in mixed 
lymphocyte culture (i.e., HLA-D), however, were not involved in this effort.

\section{Introduction}

Stimulatory and inhibitory interactions, manifested by cells and cell-derived products, have been implicated in the regulation of pluripotential and lineage-committed bone marrow hematopoietic progenitor cells in vitro and in vivo $(1,2)$. Some of these regulatory interactions are aberrant during leukemia and may be associated with the progression of the disease $(1,2)$.

A leukemia-associated inhibitory activity (LIA) ${ }^{1}(3-6)$ that suppresses the formation in vitro of colonies and clusters from HLA-DR $^{+}$(Ia-like antigen ${ }^{+}$) subpopulations of cycling colonyforming unit-granulocyte-macrophage (CFU-GM) (7-9), multipotential colony-forming unit-granulocyte, erythroid, macrophage, megakaryocyte (CFU-GEMM) (10), and burst-forming units erythroid (BFU-E) (10) progenitor cells of normal donors, but not from HLA-DR ${ }^{-}$cycling progenitor cells from patients with leukemia (7), has been identified as acidic isoferritins (11). Acidic isoferritin-inhibitory activity (AIFIA), under normal conditions, is produced and released from bone marrow and blood cells of the mononuclear phagocyte lineage (monocytes and macrophages) (12) but is found in greater concentrations in cells from patients with leukemia (3-6). Blast progenitor cells from patients with leukemia are insensitive to inhibition by AIFIA (13) and abnormalities in AIFIA interactions have been detected in mice infected with Abelson $(12,14)$ and Friend virus $(15,16)$. We had suggested that AIFIA might be physiologically relevant $(11,12)$ and that it might confer a proliferative advantage to abnormally responsive leukemia progenitor cells and thus also be relevant pathologically $(3-7,11,12,14)$. Others have also suggested its relevance in leukemia $(13,15)$.

Information on how the release of AIFIA from monocytes is controlled under normal conditions would help us to better understand its potential relevance physiologically and pathologically. Lymphocyte-monocyte interactions (17-21) and the involvement of the human HLA-DR and murine Ia-antigens have been implicated in the regulation of immune responsiveness $(17,18,22)$ and in the regulation of myelopoiesis $(7-10,23-$ 27). The present study demonstrates that the modulation of the release of AIFIA from human monocytes is restricted genetically by HLA-DR at a subpopulation level of T lymphocyte-monocyte interactions.

1. Abbreviations used in this paper: AIFIA, acidic isoferritin-inhibitory activity; BFU-E, burst-forming unit-erythroid; $C^{\prime}$, complement; CFUGM, colony-forming unit-granulocyte-macrophage; CFU-GEMM, colony-forming unit-granulocyte, erythroid, macrophage, megakaryocyte; $\mathrm{CM}$, conditioned medium; $\mathrm{E}^{+}, \mathrm{E}^{-}$, E-rosette positive and negative, respectively; FBS, fetal bovine serum; GM-CSF, granulocyte-macrophage colony-stimulating factors; LIA, leukemia-associated inhibitory activity; MLC, mixed lymphocyte culture; PBMC, peripheral blood mononuclear cells.

\section{Methods}

Cells and cell separation procedures. Bone marrow and blood cells were obtained from normal healthy donors who had given informed consent. The cells were separated by Ficoll-hypaque (density $1.07 \mathrm{~g} / \mathrm{cm}^{3}$; Pharmacia Fine Chemicals, Piscataway, NJ) and adherence in $10 \%$ fetal bovine serum (FBS, HyClone, Logan, UT) to plastic tissue culture dishes (35 mm, No. 25000, Corning Glass Works, Corning, NY) for $1.5 \mathrm{~h}$ at $37^{\circ} \mathrm{C}$. Nonadherent cells were collected by gently swirling the dishes and slowly pipetting off the culture medium. The dishes were washed three times and the washes were discarded. Adherent cells were removed by gentle scraping of the dishes with a rubber policeman. Mononuclear (low density) blood cells were also subjected to removal of phagocytic cells with iron filings using lymphocyte separator reagent (Technicon Instruments Corp., Tarrytown, NY) and to removal of adherent cells using Sephadex G-10 (Pharmacia Fine Chemicals) (28). In some cases, nonadherent cells isolated after incubation on plastic were isolated further with lymphocyte separator reagent or Sephadex G-10 to remove remaining phagocytic and adherent cells. Nonadherent and/or nonphagocytic cells were separated into E-rosette positive $\left(E^{+}\right)$and negative $\left(E^{-}\right)$ populations with neuraminidase-treated sheep erythrocytes (29). Rosetteforming cells ( $>3$ sheep erythrocytes/lymphocyte) were treated with Trisammonium chloride, to lyse the sheep erythrocytes and washed three times.

Lymphocytes were selectively removed from cell populations by pretreating cells with monoclonal antibodies plus complement as described below. The following monoclonal antibodies were used: Pan Tantibodies OKT3 (30) (Ortho Diagnostic Systems, Inc., Raritan, NJ) and T101 (31) (Hybritech Inc, San Diego, CA) were purchased. OKT4 which recognizes the human inducer-helper $T$ lymphocyte subset (32) and OKT8, which recognizes the human suppressor-cytotoxic T lymphocyte subset (33), were purchased from Ortho Diagnostic Systems, Inc. OKT9, which recognizes transferrin receptors (34) and OKT11a, which recognizes E-rosette ${ }^{+}$cells (35) were kind gifts from Dr. J. Schindler, Ortho Diagnostic Systems, Inc. Lymphocytes and monocytes were also treated with monoclonal anti-human HLA-DR (Ia-like) antigen (NE1011) purchased from New England Nuclear (Boston, MA). It had been isolated from hybrid $7.2(36)$, is an $\mathrm{IgG}_{2 \mathrm{~b}}$ antibody purified by affinity chromatography with protein $A$ and is $>95 \%$ homogeneous. It recognizes two polypeptides of 28,000 and 33,000 daltons (New England Nuclear communication). Supernatants containing the monoclonal Mac-1 antibody (37) were obtained from Dr. Peter Ralph (Sloan-Kettering Institute, New York) from hybridoma cells received from Dr. T. Springer (Harvard Medical School, Boston, MA). Two murine monoclonal noncomplementfixing HLA-A, B, C, antibodies were used as controls for HLA-DR antibodies in blocking experiments. Both detected a common HLA class I framework determinant shared by HLA-A, B and C antigens. One, KF 161, was kindly provided by Drs. R. Knowles and N. Flomenberg, Sloan-Kettering Institute, New York, and the other was purchased from Bethesda Research Laboratories, Bethesda, MD.

To obtain highly enriched subsets of T cells, $E$ rosette-positive cells were separated also by a panning procedure modified from Wysocki and Sato (38). Briefly, 2-3 $\times 10^{7} \mathrm{E}^{+}$cells were treated in $2 \mathrm{ml}$ of OKT4 or OKT8 antibody solution, respectively, at a dilution of $1: 50$, in medium for $\mathbf{4 0} \mathrm{min}$ on ice, washed twice, and brought up in phosphate-buffered saline (PBS) containing 4\% FCS. Panning dishes were prepared by coating Fisher bactodishes (100-mm diam, Fisher Scientific Co., Pittsburgh, PA; No. 8-757-12) with 3.3 or $10 \mu \mathrm{g} / \mathrm{ml}$ affinity purified goat-anti-mouse IgG (Boehringer Mannheim Diagnostics, Inc., Houston, TX) in $0.05 \mathrm{M}$ Tris- $\mathrm{HCl}, \mathrm{pH}$ 9.5. Dishes were washed four times with PBS. 
$2-3 \times 10^{7}$ antibody-treated cells were incubated on these dishes for $70 \mathrm{~min}$ at $4^{\circ} \mathrm{C}$. Negatively selected cells were harvested by gentle resuspension and slow pipetting. Only the cells in the first volume coming off the dishes were used for subsequent experiments. Negatively selected cells had no detectable antibody bound to their surface as judged by fluorescence-activated cell sorter analysis. For these studies, only the negatively selected cells were used, since positively selected cells retained significant amounts of the antibody used for the panning procedure.

The purity of individual blood cell types isolated by the above procedures was determined by staining with Wright's Giemsa, nonspecific esterase (39), and with monoclonal antibodies using immunofluorescence (Ortho Diagnostic Systems, Inc. communication) with a fluorescence activated cell sorter (FACS IV, Becton-Dickinson \& Co., Sunnyvale, CA) or by direct fluorescent microscopy. Purity of rosette-positive cells was also determined by rerosetting with neuraminidase-treated sheep erythrocytes. E-rosette-positive cells were $95 \%$ or greater T lymphocytes as determined by rerosetting and by immunofluorescence with T-101 and OKT3. The low density adherent cell fraction contained $90-98 \%$ monocytes. Treatment of cells with specific antibodies in the presence of complement $\left(C^{\prime}\right)$ removed all or $>98 \%$ of the cells staining with that particular antibody. No cell kill was detected in the presence of antibody, when $C^{\prime}$ was not used, or in the presence of $C^{\prime}$ without antibody.

Complement-dependent cytotoxicity and complement-independent studies. These procedures have been described previously $(23,25)$. In brief, $1-2 \times 10^{6} \mathrm{cells} / \mathrm{ml}$ in $10 \%$ were incubated with the appropriate final dilution of monoclonal antibody at $4^{\circ} \mathrm{C}$ for $30 \mathrm{~min}$. The cells were washed twice and then incubated with $\mathrm{C}^{\prime}$ at $37^{\circ} \mathrm{C}$ for $45 \mathrm{~min}$. The cells were then washed three times and unless otherwise stated, brought up to the original volume and contained the starting number of cells minus those killed by the $C^{\prime}$-dependent cytotoxicity procedure. Rabbit complement (Low-tox-H, Accurate Chemical \& Scientific Corp., Westbury, $\mathrm{NY}$ ) was used at a dilution that was found to give maximum killing when used with the monoclonal antibodies. This was usually a 1:8 final dilution. Cells were washed at least two times after each treatment procedure.

Preparation of corditioned medium (CM) for AIFIA. Cells were incubated at $37^{\circ} \mathrm{C}$ in tissue culture dishes (Corning Glass Works) in $1 \mathrm{ml}$ of enriched McCoy's 5A medium (as described below) with $10 \%$ heatinactivated $\left(56^{\circ} \mathrm{C}\right.$ for $30 \mathrm{~min}$ ) FBS (HyClone) and in the presence of $10^{-6} \mathrm{M}$ indomethacin (Sigma Chemical Co., St. Louis, MO) to prevent endogenous synthesis of prostaglandins that can suppress colony and cluster formation (2). CM was collected after $24 \mathrm{~h}$ unless otherwise noted. In some cases, the $C M$ was preincubated with a 1:50 final dilution of goat anti-human heart ferritin antiserum or this antiserum adsorbed with basic isoferritins ( $\mathrm{pH}>5.6)$. These antisera were a kind gift from Dr. Marianne Dorner, University of Heidelberg, Federal Republic of Germany, and their relative specificities for the acidic isoferritins have been reported previously (11).

Assay for AIFIA. CM was assessed for its capacity to suppress colony ( $>50$ cells per aggregate) and cluster (3-50 cells/aggregate) formation of human bone marrow granulocyte-macrophage progenitor cells (CFUGM) stimulated by exogenously supplied granulocyte-macrophage colony stimulatory factors (GM-CSF). $1 \times 10^{5}$ low density or, in some cases, $1 \times 10^{5}$ nonadherent low density bone marrow cells were suspended in $1 \mathrm{ml}$ of $0.3 \%$ agar culture medium (Difco Laboratories, Detroit, MI) that included McCoy's 5A medium supplemented with additional essential and nonessential amino acids, glutamine, serine, asparagine, and sodium pyruvate (Gibco Laboratories, Grand Island, NY) and contained $10 \%$ heat-inactivated FBS. No background colonies and only rare clusters (up to 20) were observed under these conditions when no exogenous stimulatory factors were supplied. GM-CSF was present in medium conditioned by either the GCT cell line (Gibco Laboratories) (40) or the 5637 cell line (41). These sources of GM-CSF are free of AIFIA, stimulate maximal clonal growth, and allow for increased detection of the sensitivity of CFU-GM to AIFIA $(12,42)$. Test CM, undiluted and diluted, were mixed at $10 \% \mathrm{vol} / \mathrm{vol}$ with the GM-CSF and the suspensions of bone marrow cells before gelling of the agar culture medium. Cultures were incubated at $37^{\circ} \mathrm{C}$ in a humidified atmosphere of $5 \% \mathrm{CO}_{2}$ in air and scored for colonies and clusters after $7 \mathrm{~d}$ of incubation, a time previously determined to be optimal for detecting AIFIA. In some experiments the inhibitory activity from monocyte $\mathrm{CM}$ was compared with a titration curve of purified acidic isoferritins ( $\mathrm{pH}<5.0)(11)$.

Between 30 and 100 colonies and 80 and 400 colonies plus clusters formed in the presence of GM-CSF and in the absence of test CM. Suppression by $\mathrm{CM}$ was similar whether colonies or colonies plus clusters were evaluated and in most cases results given are for colonies plus clusters, which represent a more accurate approximation of the total CFU-GM compartment than colonies alone (2). Three to five plates were scored for such samples and the results are given as the mean \pm SE. The probability of significant differences between samples was determined by use of $t$ test.

HLA typing and cell donor selection. Peripheral blood mononuclear cells (PBMC) were isolated by Ficoll hypaque density-gradient centrifugation. Typing for HLA-A, B, and C antigens was performed by using the standard National Institutes of Health two-stage complement-dependent microcytotoxicity test. A panel of 142 highly selected anti-HLA antisera were used. The serum panel represents two or three antisera for each of the currently defined HLA specificities. Typing for DR antigens was performed using a modified microcytotoxicity test with nylon-column-purified B-lymphocytes as test cells.

The studies on lymphocyte-monocyte interactions by cells from first degree relatives were performed on blood samples obtained from HLA genotyped, heterozygous families. Two unrelated pairs of HLA identical siblings were studied (four combinations). HLA haploidentical first degree relatives were investigated with PBMC obtained from families, where the HLA-incompatible haplotypes were serologically different for all HLA determinants from the genotypically identical HLA haplotype. Allogeneic, unrelated HLA-different PBMC as well as autologous PBMC were included in each test.

PBMC from unrelated individuals were selected for the studies based on their HLA phenotype and genotype. Two unrelated HLA-identical mixed lymphocyte culture (MLC) unreactive cell combinations (GK and RB) with the HLA genotype A1;Cw7;B8;DR3/A1;Cw7;B8;DR3 were tested. Three unrelated HLA-DR identical pairs were also investigated (MZ, LR and RM). The HLA genotypes for these cells were MZ: Aw24;Cw2;B14;DR1/Aw24;Cw2;B14;DR1, LR: Aw23;C-; B14;DR1/A28;C-; B14; DR 1, and RM: A2; Cw5; Bw44; DR1/ A2;Cw4;Bw35;DR1. The MLC testings of the cell combinations MZ/ LR; MZ/RM and LR/RM in one-way MLC revealed low responses (relative response 10-25\%). These responses are compatible with HLAD/DR homozygosity of the PBMC. The cell combinations MZ and LR also shared HLA-B14 in addition to DR1 while the combinations MZ and RM, and LR and RM only shared DR1.

Two different unrelated pairs of HLA haploidentical cell combinations were tested, GK and RD, and RB and RD. Each of these pairs shared the HLA-A1;Cw7;B8;DR3 haplotype. Three pairs of unrelated HLADR haploidentical combinations were also tested $M Z$ and NF, LR and NF, and RM and NF. The HLA genotype of NF was A28;Cw8;B14;DR1/ A26;C-;Bw41;DR3. The cell combinations MZ and NF shared HLA$B 14$ in addition to DR1. The cell combination LR and NF shared A28 
and B14 in addition to DR1, while the cell combination RM and NF only shared DR1. The one-way MLC testing between the HLA haploidentical and HLA-DR haploidentical unrelated combination were strongly positive for GK:RDx; RB:RDx; MZ:NFx; LR:NFx; and NF:RMx ( $x$ denotes $x$-irradiated stimulating cells). The combinations RD:GKx; RD:RBx; NF:MZx; NF:LRx and NF:RMx demonstrated a weak positive response (relative response $10-25 \%$ ) compatible with a HLA-D typing response (43). These typing responses were obtained because of the HLA-D/DR homozygosity of the stimulating cells GK, RB (i.e., HLA-Dw3/DR3), MZ, LR, and RM (i.e., HLA-Dw1/DR1).

\section{Results}

AIFIA derives from an $H L A-D R^{+}$subpopulation of human monocytes. It has been shown that monocytes and macrophages under normal conditions, contain and release AIFIA (12). To define the cellular source of this release further, adherent mononuclear blood cells (90-95\% monocytes, <2\% PMN, 3-9\% lymphocytes) were treated with control medium, $\mathrm{C}^{\prime}$ or monoclonal antibodies in the presence of $\mathrm{C}^{\prime}$, to remove T, HLA-DR ${ }^{+}$- and Mac- $1^{+}$-cells. AIFIA release from monocytes was first detected after 12-15 h, was maximal after 24-48 $\mathrm{h}$ and was no longer detected after 3-4 d. The data in Fig. 1 represent the average results of assaying medium conditioned by these treated cells from 3 to 5 normal donors for $24 \mathrm{~h}$, undiluted and diluted, for inhibition of colony and cluster formation of bone marrow cells stimulated by an exogenous source of GM-CSF. Undiluted CM from $10^{6}$ adherent mononuclear cells (monocytes) $/ \mathrm{ml}$ reduced significantly $(P<0.0005)$ colony and cluster formation by $\sim 50 \%$ and dilution of this $\mathrm{CM}$ resulted in a plateau curve of inhibition at $\sim 50 \%$ over $7 \log$ dilutions, a curve similar to that detectable with AIFIA (11). CM from $10^{5}$ monocytes $/ \mathrm{ml}$ released $2 \mathrm{log}$ units less activity and $\mathrm{CM}$ from $10^{4}$ monocytes $/ \mathrm{ml}$ demonstrated plateau levels of inhibitory activity only when undiluted. Inhibitory activity was not detected in CM prepared from $10^{2}$ to
$10^{3}$ monocytes $/ \mathrm{ml}$. Results were similar whether the adherent mononuclear blood cells were treated with control medium or $\mathrm{C}^{\prime}$. The inhibitory activity present in $\mathrm{CM}$ from $10^{5}$ to $10^{6}$ monocytes $/ \mathrm{ml}$ was inactivated by pretreatment of $\mathrm{CM}$ with goat antihuman heart ferritin antiserum, which is relatively specific for the acidic isoferritins (11). The inhibitory activity was also inactivated by pretreatment of $\mathrm{CM}$ with goat anti-human heart ferritin antiserum that was first adsorbed with basic isoferritins and which then did not recognize the basic isoferritins but did recognize the acidic isoferritins (data not shown). This substantiates that the inhibitory activity is of the acidic isoferritin type. Complete removal of the remaining $1-4 \% \mathrm{~T}$ cells from the adherent mononuclear cell fraction using monoclonal antibodies (i.e., T101, OKT3, OKT9, and OKT11a) in the presence of $C^{\prime}$ had no effect on the release of AIFIA from $10^{6}$ adherent mononuclear cells $/ \mathrm{ml}$. The effective removal of the $T$ cells in the treated samples was verified by indirect immunofluorescence testing. These fractions contained $\geq 98 \%$ monocytes. This demonstrated that $T$ cells were not necessary for the release of AIFIA from monocytes. Treatment of monocytes with anti-HLA-DR in the presence of $C^{\prime}$ killed $40-60 \%$ of the monocytes. The population of monocytes left did not release AIFIA. Treatment of monocytes with anti-Mac 1 plus $C^{\prime}$ yielded similar results, suggesting that AIFIA derives from a subpopulation of monocytes with the HLA-DR ${ }^{+}$-, Mac-1 ${ }^{+}$-antigenic phenotype or that such cells may be needed for the release of AIFIA from other monocytes.

Release of AIFIA is modulated by specific subpopulations of lymphocytes. Blood lymphocytes do not contain or release AIFIA (12) and as shown in Fig. 1, are not necessary for AIFIA release from monocytes. However, preliminary experiments demonstrated that autologous nonadherent and/or nonphagocytic mononuclear blood cells ( $>98 \%$ lymphocytes, $1 \%$ PMN, $<0.25 \%$ nonspecific esterase staining) could modulate the release

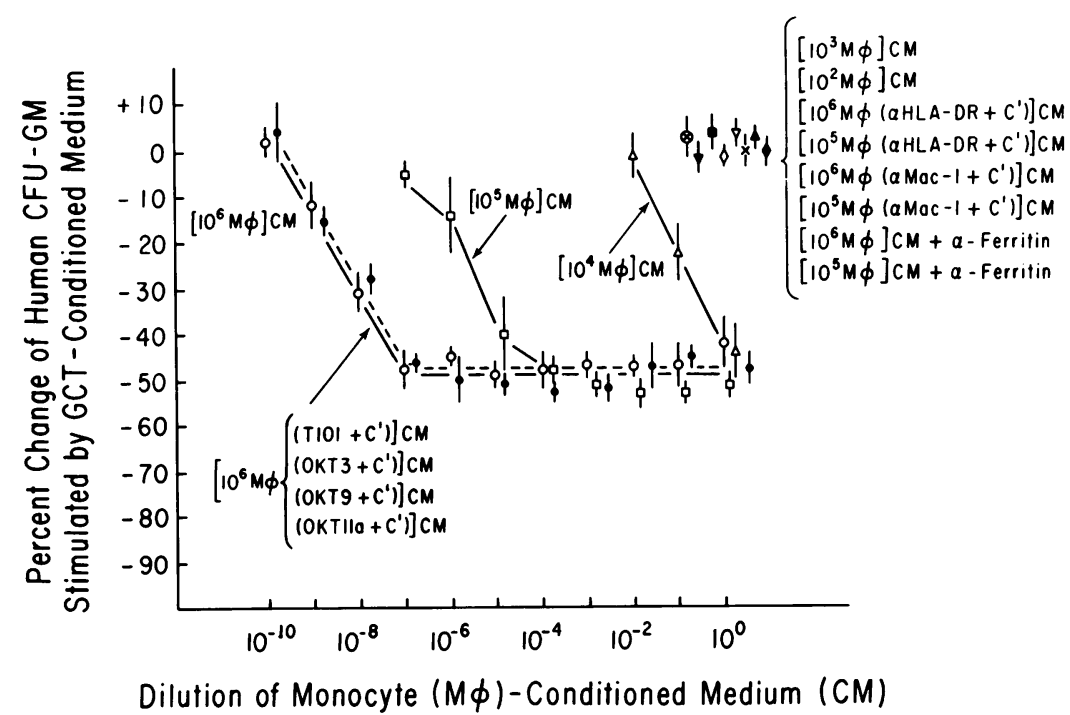

Figure 1. Release of inhibitory activity from human monocytes. Inhibitory activity is released from $10^{4}$ to $10^{6}$ monocytes $/ \mathrm{ml}$ but not from $10^{2}$ to $10^{3}$ monocytes $/ \mathrm{ml}$. The inhibitory activity is inactivated by preincubation with anti-acidic isoferritin antiserum demonstrating that it is AIFIA. AIFIA derives from an HLA-DR ${ }^{+}, \mathrm{MAC}^{-} 1^{+}$subpopulation of monocytes, and $\mathrm{T}$ lymphocytes are not required for this release. Cell concentrations after treatment with antibody plus $C^{\prime}$ were equal to that shown less the number of cells killed. Thus, there were actually $\sim 5 \times 10^{5}$ monocytes in the fraction designated $10^{6}$ $\mathrm{M} \phi$ (monocytes) (HLA-DR $+\mathrm{C}^{\prime}$ ) since $\sim 50 \%$ of the monocytes were killed by this treatment. Since few $T$ lymphocytes were in the monocyte fraction the numbers shown are a closer approximation of the actual numbers of cells present. 


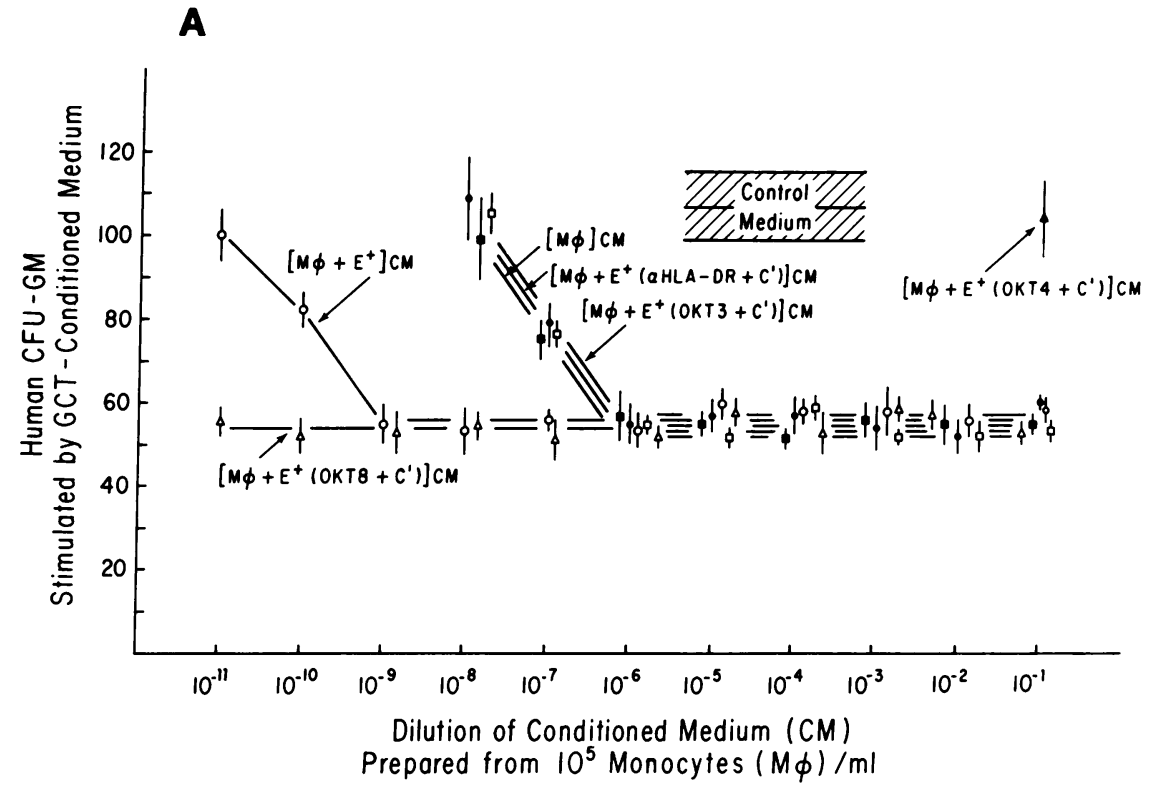

Figure 2. Release of AIFIA from human monocytes is enhanced $(A)$ and induced $(B)$ by a population of $\mathrm{OKT} 4^{+}$E-rosette ${ }^{+}$-lymphocytes (treated with OKT8 $+\mathrm{C}^{\prime}$ ), and suppressed by a population of $\mathrm{OKT}^{+} \mathrm{E}$-rosette ${ }^{+}$-lymphocytes (treated with OKT4 $\left.+\mathrm{C}^{\prime}\right)(A)$. The enhancing and suppressing influences are removed by pretreating lymphocytes with 1:200 dilutions of OKT3 or HLA-DR monoclonal antibodies in the presence of complement before adding these cells to monocytes conditioning culture medium. M $\phi$, monocytes.

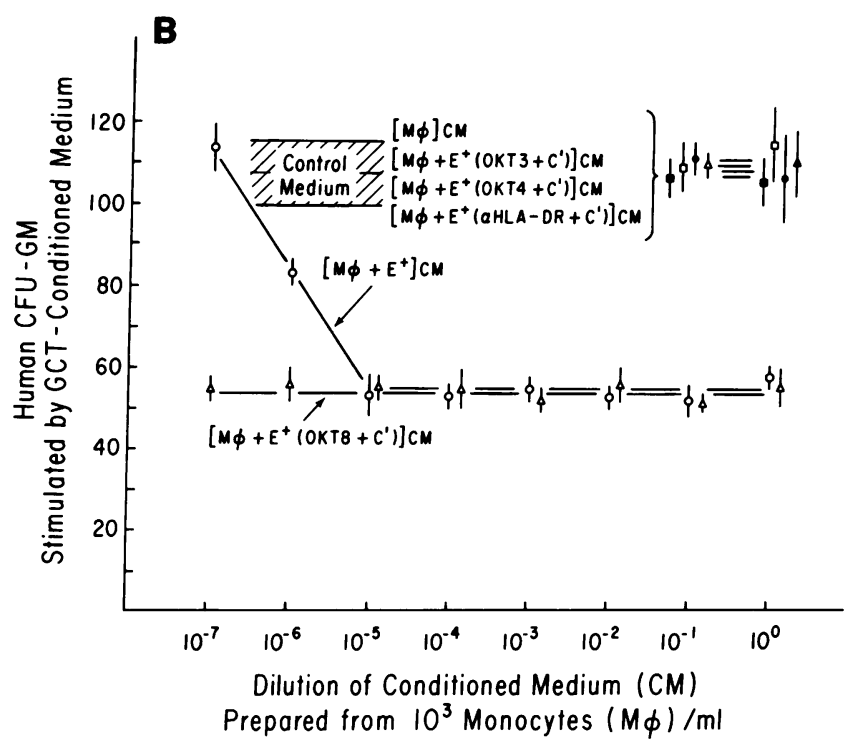

of AIFIA from monocytes. Thus, $10^{6}$ lymphocytes $/ \mathrm{ml}$ induced the release of greater levels of AIFIA from $10^{5}$ monocytes $/ \mathrm{ml}$, and $10^{4}$ lymphocytes completely suppressed the release of AIFIA from this concentration of monocytes. This suggested a role for subpopulations of lymphocytes in the release of AIFIA from monocytes. The results of a single representative experiment assessing the influence of autologous subpopulations of E-rosettepositive lymphocytes $\left(\mathrm{E}^{+}\right.$cells) on release of AIFIA from $10^{5}$ monocytes/ml (Fig. $2 A$ ) and $10^{3}$ monocytes $/ \mathrm{ml}$ (Fig. $2 B$ ) are demonstrated. The adherent mononuclear cell fraction was depleted of $\mathrm{T}$ cells by treatment with OKT3 plus $\mathrm{C}^{\prime}$. The OKT $8^{+}$- enriched fraction of $\mathrm{E}^{+}$cells was obtained by treating nonadherent $\mathrm{E}^{+}$cells with $\mathrm{OKT} 4$ plus $\mathrm{C}^{\prime}$ and the $\mathrm{OKT} 4^{+}$-enriched fraction of $\mathrm{E}^{+}$cells was obtained by treating the $\mathrm{E}^{+}$cells with OKT8 plus $\mathrm{C}^{\prime}$. The results in Fig. $2 A$, assaying $24 \mathrm{~h} \mathrm{CM}$, demonstrated that $10^{5}$ E-rosette-positive cells increased the release of AIFIA from $10^{5}$ monocytes $/ \mathrm{ml}$ and that $\mathrm{OKT}^{+}$ $\left(=E^{+}\left[O K T 8+C^{\prime}\right]\right)$ cells increased this release further. An opposite effect was noted with $\mathrm{OKT}^{+}\left(=\mathrm{E}^{+}\left[\mathrm{OKT} 4+\mathrm{C}^{\prime}\right]\right)$ cells, which totally suppressed the release of AIFIA from $10^{5}$ monocytes $/ \mathrm{ml}$. Both the enhancing and suppressing influences of the lymphocyte subpopulations in AIFIA release from monocytes was removed by pretreating the $\mathrm{E}^{+}$cells with anti-HLA-DR or OKT3 plus $C^{\prime}$, before culturing these cells with the monocytes. That the enhancing activity of the $\mathrm{OKT}^{+}$cells was actually an induction of AIFIA release is seen in Fig. $2 B$. No AIFIA release was apparent with $10^{3}$ monocytes $/ \mathrm{ml}$, but plateau levels of inhibitory activity $(P<0.0005)$ were apparent when $10^{5} \mathrm{E}^{+}$or $\mathrm{OKT}^{+}{ }^{+}$cells were added. The $\mathrm{OKT} 8^{+}$cell fraction had no inducing influence and the inducing influence of the $\mathrm{E}^{+}$cells was lost upon pretreatment of the $\mathrm{E}^{+}$fraction with OKT3 or antiHLA-DR plus $C^{\prime}$, before culturing of these cells with monocytes. $\mathrm{OKT}^{+}$and $\mathrm{OKT}^{+}$cells by themselves did not release AIFIA. Medium conditioned by these $T$ cells when mixed with purified acidic isoferritins or monocyte $\mathrm{CM}$ does not influence the inhibitory activities of these preparations (data not shown). Medium conditioned by culturing $10^{5}$ monocytes $/ \mathrm{ml}$ contained measurable amounts of AIFIA only during the time period of $15-48 \mathrm{~h}$. Medium conditioned by $10^{5}$ monocytes $/ \mathrm{ml}$ plus $10^{5}$ $\mathrm{OKT}^{+}$cells, however, contained AIFIA from $15-96 \mathrm{~h}$ of culture. In contrast, medium conditioned for 3-168 $\mathrm{h}$ by monocytes in the presence of $10^{5} \mathrm{OKT} 8^{+}$cells did not contain any detectable AIFIA (data not shown). No AIFIA was found in CM under 
any conditions before $15 \mathrm{~h}$ or after $120 \mathrm{~h}$ of culture. OKT4 ${ }^{+}$ and $\mathrm{OKT}^{+}$populations of cells pretreated with anti-HLA-DR plus $C^{\prime}$ lost their respective inducing and suppressing activities over the 3-168 $\mathrm{h}$ conditioning medium period (data not shown).

The influence of the subpopulations of $T$ lymphocytes, which were obtained by complement-dependent cytotoxicity, on release of AIFIA from monocytes was substantiated by using $\mathrm{OKT} 8^{+} \mathrm{E}^{+}$ and $\mathrm{OKT} 4^{+} \mathrm{E}^{+}$cells obtained by sorting for these cells using a panning procedure (38). The results of four experiments with $\mathrm{OKT}^{+} \mathrm{E}^{+}$cells duplicated the results seen with $\mathrm{E}^{+}(\mathrm{OKT} 4$ $\left.+\mathrm{C}^{\prime}\right)$ cells and the results with $\mathrm{OKT} 4^{+} \mathrm{E}^{+}$cells duplicated the results with $\mathrm{E}^{+}\left(\mathrm{OKT} 8+\mathrm{C}^{\prime}\right)$ cells. The purity of the OKT8 $8^{+}$ and $\mathrm{OKT}^{+}{ }^{+}$cells obtained by panning ranged from 88 to $97 \%$ ( $n=4$ experiments). In the experiment in which $97 \%$ purity for $\mathrm{OKT}^{+}{ }^{+}$or $\mathrm{OKT} 4^{+}$cells was obtained, the influence of varying concentrations of these cells was assessed on AIFIA release from monocytes (Fig. 3). The release of AIFIA from $10^{5}$ monocytes was suppressed completely by $10^{5} \mathrm{OKT}^{+}$cells and suppressed slightly by $10^{4} \mathrm{OKT}^{+}$cells (Fig. $3 \mathrm{~A}$ ). The release of AIFIA from $10^{3}$ monocytes was induced by $10^{5}$ and $10^{4} \mathrm{OKT} 4^{+}$cells with $10^{5} \mathrm{OKT}^{+}$cells inducing $3 \log$ units more activity than the $10^{4}$ cells (Fig. $3 \mathrm{~B}$ ). The OKT ${ }^{+}$cells by themselves did not release AIFIA. Additionally, the suppressive influence of the $\mathrm{OKT}^{+}$cells and the inducing influence of the $\mathrm{OKT} 4^{+}$cells were lost by treating these cells with anti-HLA-DR plus $C^{\prime}$ (data not shown). These results implicated HLA-DR positive $T$ cell subpopulations in the modulation of release of AIFIA from monocytes.

The amount of AIFIA released over a 24 -h period from monocytes was determined in six separate experiments by comparative analysis with the titration curve of a known concentration of purified acidic isoferritins. 100,000 monocytes $/ \mathrm{ml}$, in the absence of $\mathrm{T}$ lymphocytes released $10^{-9}$ to $10^{-10} \mathrm{~g}$ AIFIA. 1,000 monocytes $/ \mathrm{ml}$ in the presence of $10^{5} \mathrm{OKT}^{+}$cells released $10^{-10}$ to $10^{-12} \mathrm{~g}$ AIFIA.

Role for HLA-DR in the modulation of the release of AIFIA from monocytes by subpopulations of lymphocytes. The involvement of HLA-DR ${ }^{+}$subpopulations of monocytes and lympho-

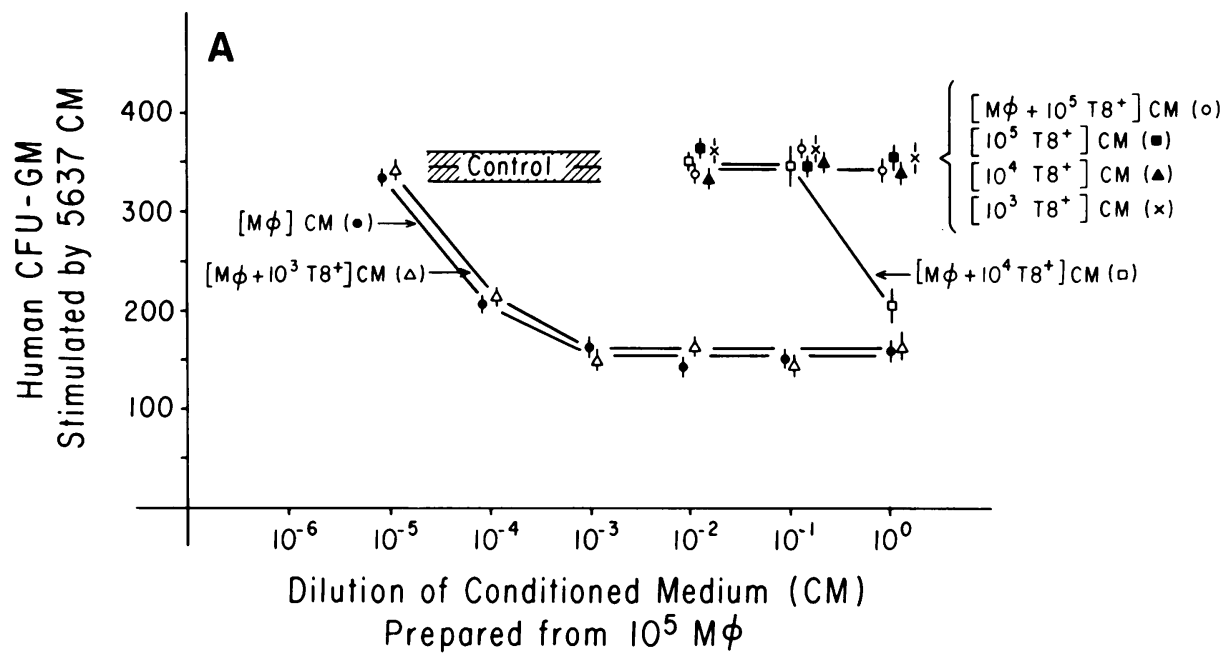

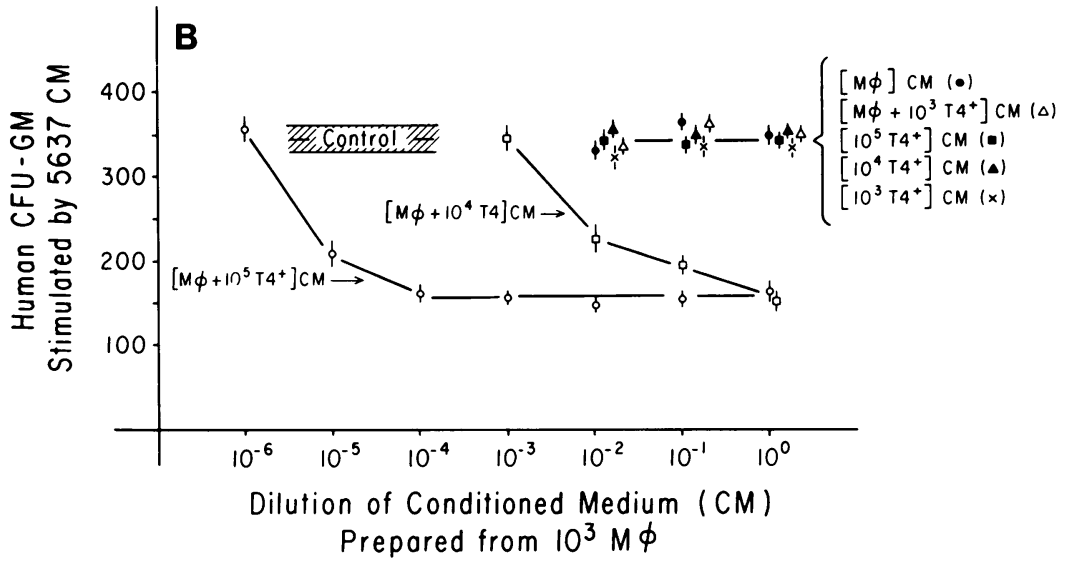

Figure 3. Release of AIFIA from human monocytes is suppressed by an $\mathrm{OKT} 8^{+} \mathrm{E}^{+}$subpopulation of lymphocytes $(A)$ and induced by an $O \mathrm{OT}^{+} \mathrm{E}^{+}$subpopulation of lymphocytes $(B)$. The $\mathrm{E}^{+}$subpopulations were obtained by sorting using a panning procedure (38). The populations of $\mathrm{E}^{+}$cells do not themselves release AIFIA. $M \phi$, monocyte. 
cytes in the release of AIFIA from monocytes suggested that HLA-DR antigenic determinants might be involved in this modulatory effect. This was assessed by determining whether anti-HLA-DR, in the absence of $C^{\prime}$, could block the suppressing and inducing effects of the lymphocytes on the monocytes. The results of one of three similar experiments are shown in Fig. 4. Pulsing monocytes with anti-HLA-DR did not prevent the release of AIFIA from $10^{5}$ monocytes/ml. Pulsing monocytes alone or lymphocytes alone with anti-HLA-DR or leaving the antibody in with the monocyte-lymphocyte mixtures blocked both the suppression effect (Fig. $4 \mathrm{~A}$ ) and the induction effect (Fig. $4 \mathrm{~B}$ ). That the HLA-DR antibody blocking of lymphocyte modulation of AIFIA release from monocytes at the level of the lymphocyte or monocyte was not due to loss of anti-HLA-DR from one cell type and acquisition by the other cell type is shown in Fig. 5. Monocytes at $10^{3}$ or $2 \times 10^{3}$ cells $/ \mathrm{ml}$ did not release AIFIA. Release of AIFIA from $10^{3}$ monocytes was induced by 1-2 $\times 10^{5} \mathrm{OKT}^{+}{ }^{+}$-enriched lymphocytes. This effect was blocked by pulsing the monocytes or lymphocytes with anti-HLA-DR.
This block was overcome by the addition of $10^{3}$ monocytes (not pulsed with HLA-DR antibody) to $10^{5}$ lymphocytes (not pulsed with anti-HLA-DR) plus $10^{3}$ monocytes (pulsed with anti-HLADR), or by the addition of $10^{5}$ lymphocytes (not pulsed with HLA-DR antibody) to $10^{3}$ monocytes (not pulsed with antiHLA-DR) plus $10^{5}$ lymphocytes (pulsed with HLA-DR antibody).

Anti-HLA-DR in the absence of $\mathrm{C}^{\prime}$ blocks the suppressive and inductive influences of the $\mathrm{T}$ lymphocyte subpopulations on release of AIFIA from monocytes. Thus, it was necessary to determine if removal of both influences by pretreating the individual $\mathrm{T}$ lymphocyte or monocyte populations with anti-HLADR in the presence of $C^{\prime}$ was due to actual kill of the cells or to a blocking action of the anti-HLA-DR. As shown in Fig. 6, removal of the suppressive and inductive influences of the $T$ lymphocyte subsets was apparent when the cells were pretreated in the presence of $C^{\prime}$ with a dilution of anti-HLA-DR that did not in the absence of $\mathrm{C}^{\prime}$ block the cellular interactions. Release of AIFIA from $10^{5}$ monocytes was not influenced by pretreating
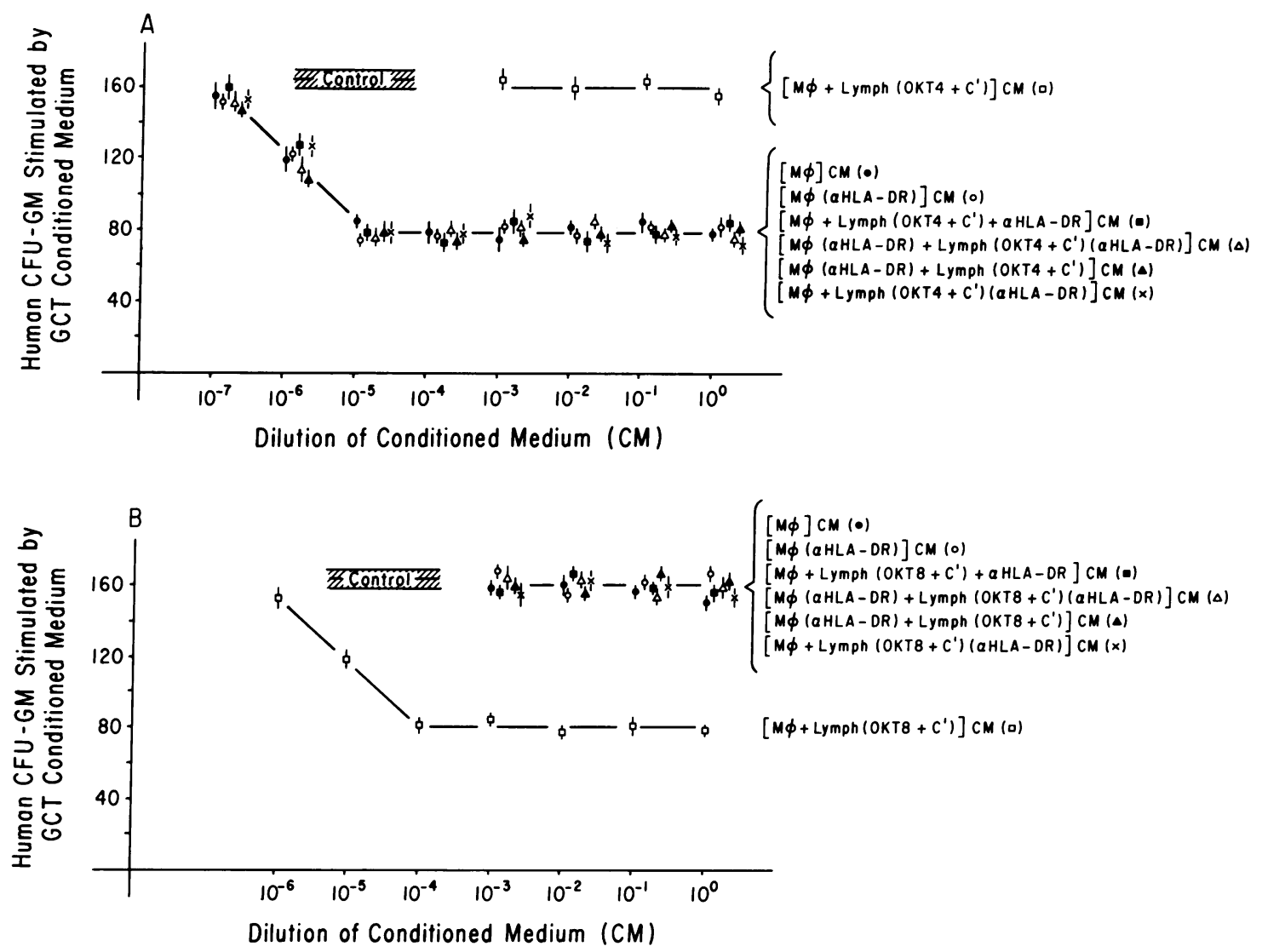

Figure 4. Monoclonal HLA-DR antibody pretreatment of monocytes or lymphocytes (lymph) blocks lymphocyte subpopulation suppression $(A)$ and induction $(B)$ of AIFIA release from human monocytes. Monocytes and/or lymphocytes were pulse treated with a 1:50 final

dilution of anti ( $\alpha$ ) HLA-DR separately and before medium was conditioned or the monocytes and lymphocytes conditioned medium in the presence of a 1:20 final dilution of HLA-DR. The plateau curve of inhibition was significant to $P<0.0005$. M $\phi$, monocyte. 


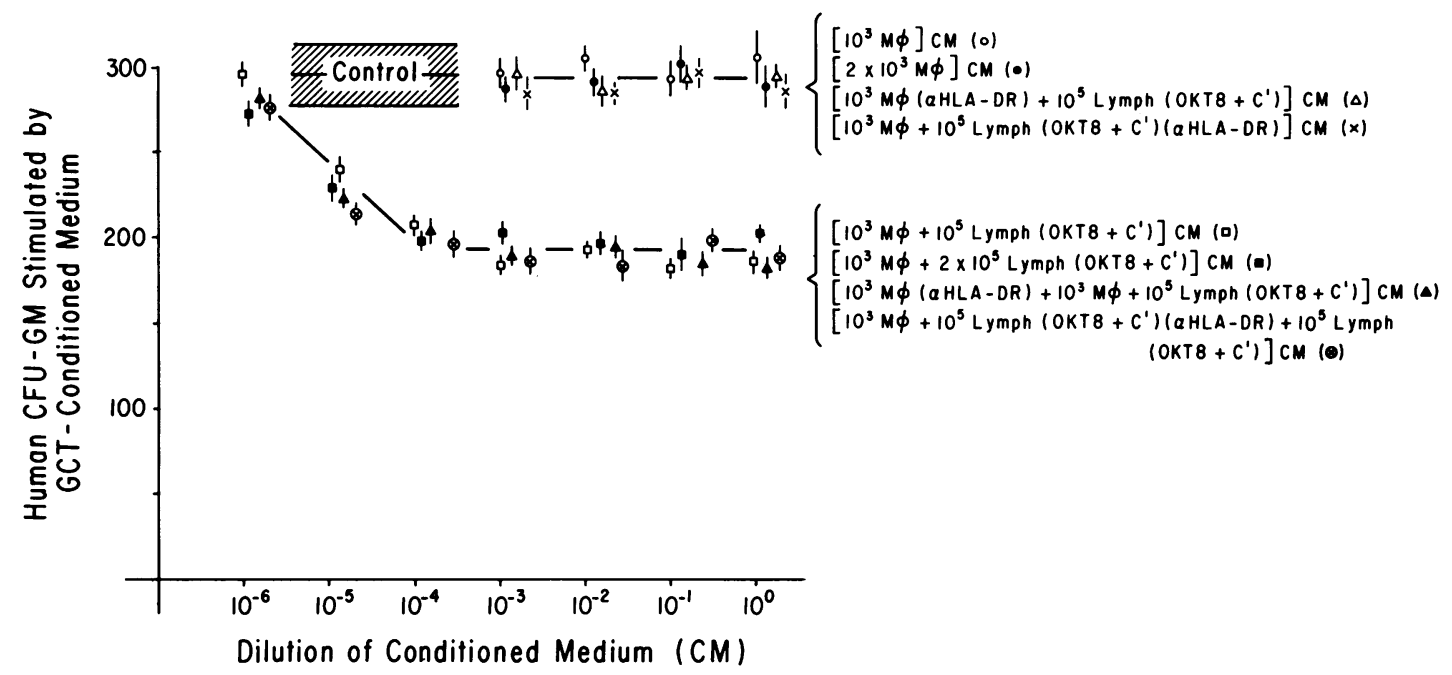

Figure 5. Monoclonal HLA-DR antibody blocking of induction of AIFIA release from monocytes by OKT4-enriched lymphocytes at the level of monocytes or lymphocytes is not due to loss of antiHLA-DR from one cell type and acquisition by another. Monocytes

or lymphocytes pulsed with a 1:50 dilution of anti ( $\alpha$ ) HLA-DR do not interfere with induction of AIFIA from monocytes not treated with $\alpha$ HLA-DR and lymphocytes not treated with $\alpha$ HLA-DR. M $\phi$, monocyte.

the monocytes with a 1:50 or 1:200 dilution of anti-HLA-DR in the absence of $C^{\prime}$. Pretreatment of monocytes with a 1:200 dilution in the presence of $\mathrm{C}^{\prime}$, which killed $50 \%$ of the monocytes, ablated the release of AIFIA (Fig. $6 A$ ). 1,000 monocytes, pretreated with anti-HLA-DR in the absence or presence of $\mathrm{C}^{\prime}$ did not release AIFIA (Fig. $6 \mathrm{~B}$ ). The suppressive (Fig. $6 \mathrm{~A}$ ) and inductive (Fig. $6 \mathrm{~B}$ ) influences of lymphocytes on release of AIFIA from monocytes was blocked by pretreating the lymphocytes or monocytes with a 1:50, but not with a 1:200 dilution, of anti-HLA-DR in the absence of $C^{\prime}$. Pretreating the cells with a 1:200 dilution of anti-HLA-DR in the presence of $\mathrm{C}^{\prime}$ ablated the influences of the lymphocytes.

To determine the specificity of the blocking interaction with anti-HLA-DR in the absence of $C^{\prime}$, two monoclonal antibodies against HLA-A, B, $C$ were used in a comparative assay. Neither of these monoclonal HLA-A, B, C antibodies was capable of blocking the OKT8-enriched lymphocyte cell suppression of AIFIA release from $10^{5}$ monocytes (Fig. $6 \mathrm{~A}$ ) or the OKT4enriched lymphocyte cell induction of AIFIA release from $10^{3}$ monocytes (Fig. $6 \mathrm{~B}$ ). The results shown are for antibody KF161, but similar results were obtained with the commercial antibody.

The results shown above suggested further that HLA-DR antigenic determinants were probably involved in the modulation of release of AIFIA.

HLA-DR compatibility of lymphocytes and monocytes is necessary for lymphocyte modulation of AIFIA release from monocytes. To elucidate further the role of HLA-DR in this situation, a series of experiments were set up to determine if these cellular interactions were restricted genetically at the level of HLA-DR antigenic determinants. In the first series of experiments, the influence of autologous vs. HLA-different allo-

geneic cell combinations was assessed (Fig. 7). In the second series, the influence of allogeneic cells from HLA genotypically identical siblings and first degree relatives was determined (Fig. 8). In the third series, the influence of allogeneic cells from unrelated donors completely matched at HLA or HLA-DR or donors who were haploidentical for HLA or HLA-DR alone was evaluated (Fig. 9). The curves in Fig. 7 are the average results of $\mathrm{CM}$ from 21 different blood donors. A total of six different marrow targets were used. The suppression of AIFIA release from $10^{5}$ monocytes $/ \mathrm{ml}$ (Fig. $7 \mathrm{~A}$ ) and the induction of AIFIA release from $10^{3}$ monocytes/ml (Fig. $7 \mathrm{~B}$ ) was apparent with autologous lymphocytes, but not with allogeneic lymphocytes that were HLA different. The lack of modulatory influence with the HLA-different allogeneic combinations was apparent regardless of which donor supplied the monocyte fraction and which donor supplied the lymphocyte fraction.

An assessment of the cell interactions with cells from related donors is shown in Fig. 8 and includes four donors who were HLA genotypically identical siblings and four donors who were HLA haploidentical first degree relatives. The suppression of AIFIA release from $10^{5}$ monocytes/ml (Fig. $8 \mathrm{~A}$ ) and the induction of AIFIA release from $10^{3}$ monocytes $/ \mathrm{ml}$ (Fig. $8 \mathrm{~B}$ ) was complete with the HLA-identical lymphocytes and monocytes. Partial suppression (Fig. $8 \mathrm{~A}$ ) and partial induction (Fig. $8 \mathrm{~B}$ ) was noted with the haploidentical cell combinations. The partial responses in the HLA-haploidentical cell combinations were similar regardless of which haploidentical donor supplied the lymphocytes and which one supplied the monocytes.

Interactions involving cell mixtures from unrelated donors matched at HLA or HLA-DR are given in Fig. 9. The HLA combinations used are shown in the legend to Fig. 9 and further 

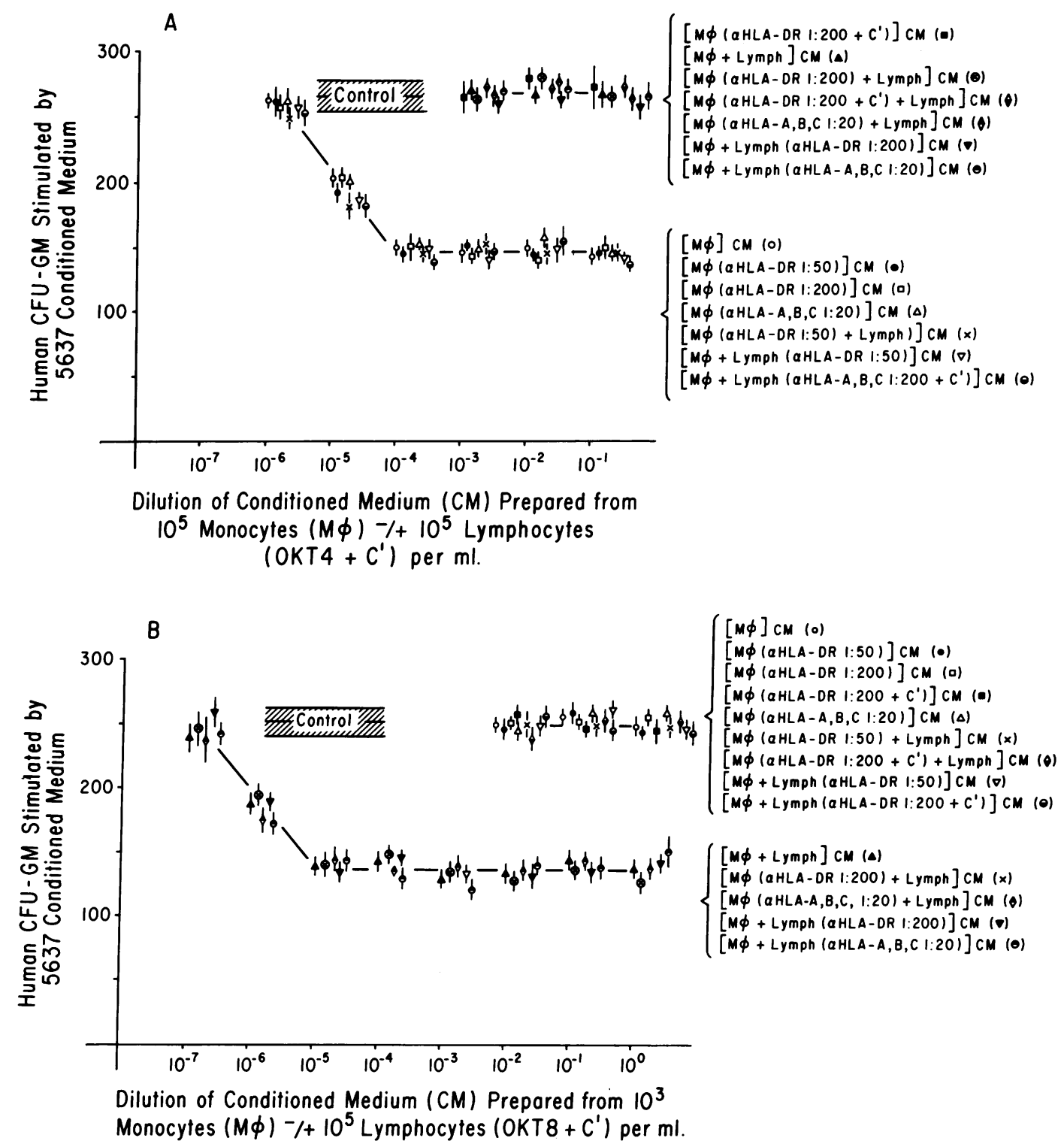

Figure 6. Suppression $(A)$ and induction $(B)$ of the release of AIFIA from human monocytes by subpopulations of lymphocytes is blocked by pulse treatment of monocytes or lymphocytes with high concentrations of anti $(\alpha)$ HLA-DR (1:50 dilution) but not by anti-HLA-A,

described in Methods. When the lymphocytes were matched for both HLA haplotypes or for both HLA-DR determinants, there was complete suppression of AIFIA release from $10^{5}$ monocytes/ml (Fig. $9 A$ ) and induction of AIFIA release from $10^{3}$ monocytes $/ \mathrm{ml}$ (Fig. 9 B). There was partial suppression (Fig. $9 \mathrm{~A}$ ) and induction (Fig. $9 \mathrm{~B}$ ) when cells were HLA haploidentical. The results were similar using HLA-DR haploidentical cells regardless of which haploidentical donor supplied the monocyte fraction and which donor supplied the lymphocyte fraction.

B, C (1:20 dilutions). Abrogation of the effects noted are apparent also by complement-dependent killing of monocytes or lymphocytes with dilutions of $\alpha$ HLA-DR (1:200) which do not block the cellular interactions. $\mathrm{M} \phi$, monocyte.

The experiments shown in Figs. 7-9 demonstrated that the lymphocytes and monocytes had to have been matched for at least one HLA-DR determinant in order for the lymphocyte subpopulations to suppress or induce AIFIA release from monocytes. The suppression and induction of AIFIA release from monocytes by their HLA-identical or HLA-DR-identical allogeneic lymphocyte subpopulation were blocked by pulsing the monocytes with anti-HLA-DR, in the absence of $C^{\prime}$, before culturing the monocytes with the lymphocyte subpopulations. 


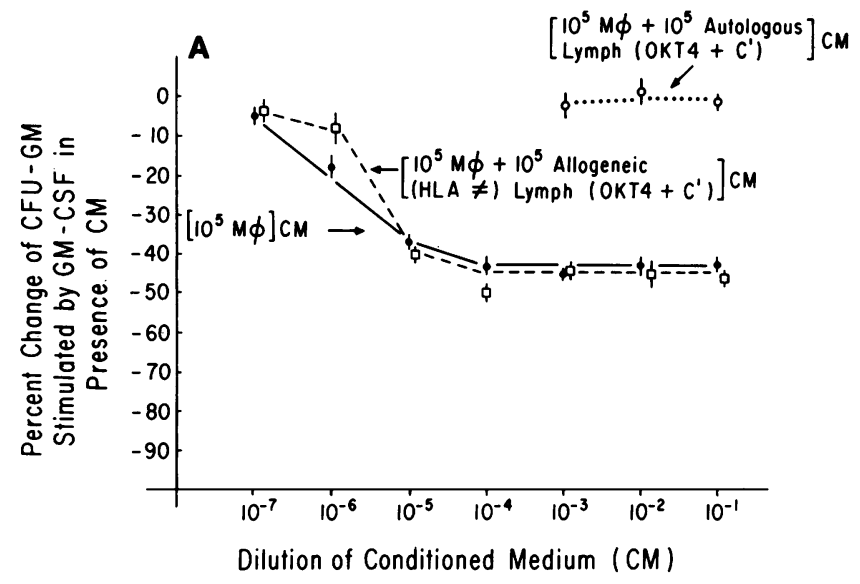

Figure 7. Release of AIFIA from human monocytes is modulated by autologous, but not by HLA-different $(\neq)$ allogeneic lymphocytes. $(A)$ Suppression of AIFIA release from $10^{5}$ monocytes $/ \mathrm{ml}$ by autologous OKT8 $8^{+}$-enriched lymphocytes (pretreated to remove $\mathrm{OKT}^{+}{ }^{+}$cells).

Similarly, the partial suppression and induction of AIFIA release from monocytes by HLA haploidentical allogeneic lymphocytes were blocked also by anti-HLA-DR antibodies (11 combinations each for suppression and induction of AIFIA release; data not shown).

Experiments were done to determine if HLA-nonidentical allogeneic cells could interfere with autologous cell interactions (Fig. 10) and if the allogeneic cell interactions led to the production of inactivators of AIFIA or to the release of factors that could suppress or induce AIFIA release from monocytes. $10^{5}$ $\mathrm{OKT}^{+}$-enriched lymphocytes from one cell donor did not sup-

A

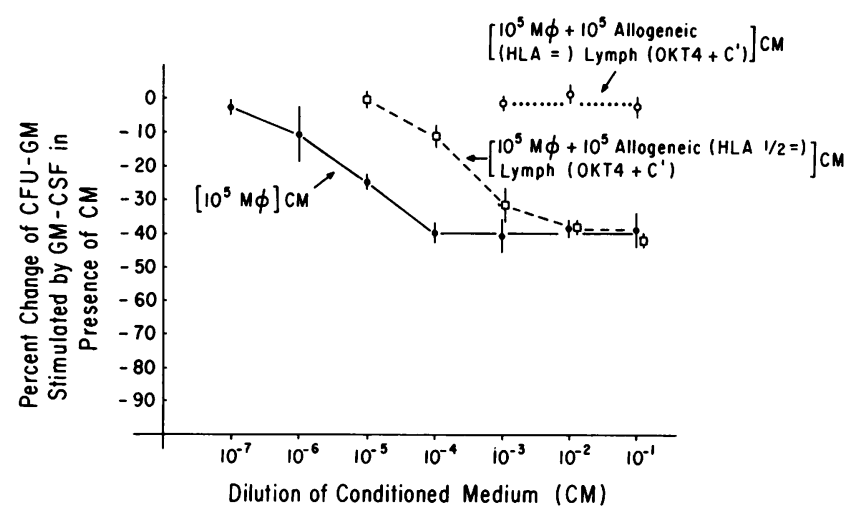

Figure 8. Related donors. Release of AIFIA from human monocytes is modulated fully by allogeneic lymphocytes from HLA genotypically identical siblings $(\mathrm{HLA}=)$ and partially by allogeneic lymphocytes from HLA-haploidentical first degree relatives (HLA 1/2=).

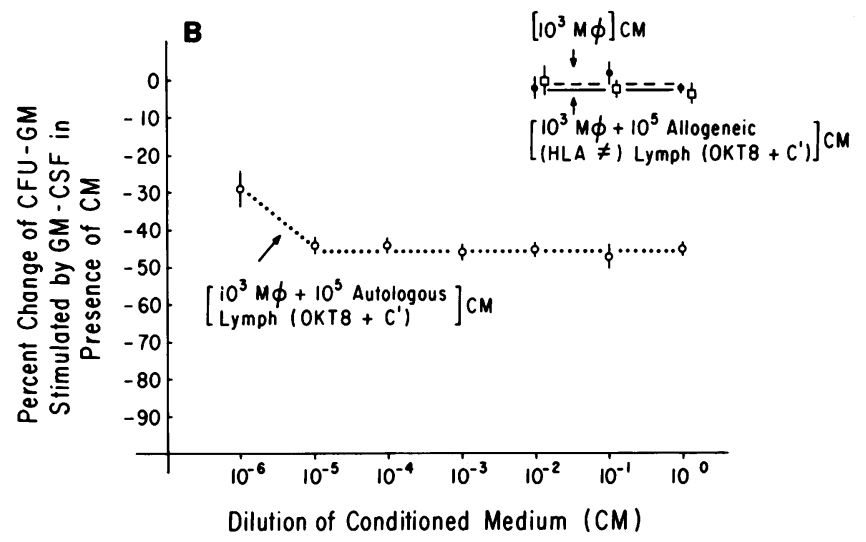

(B) Induction of AIFIA release from $10^{3}$ monocytes $/ \mathrm{ml}$ by autologous $\mathrm{OKT}^{+}$-enriched lymphocytes (pretreated to remove $\mathrm{OKT}^{+}$ cells). $\mathbf{M} \phi$, monocyte.

press the release of AIFIA from $10^{5}$ allogeneic HLA-different monocytes or interfere with suppression of AIFIA release by $10^{5}$ autologous $\mathrm{OKT}^{+}$-enriched lymphocytes (Fig. $10 \mathrm{~A}$ ). Similarly, $10^{5} \mathrm{OKT}^{+}{ }^{+}$-enriched lymphocytes from one cell donor did not induce the release of AIFIA from $10^{3}$ allogeneic, HLAdifferent monocytes or interfere with the induction of AIFIA release by $10^{5}$ autologous OKT4 $4^{+}$-enriched lymphocytes (Fig. $10 \mathrm{~B}$ ). These results suggested that allogeneic cell interactions did not release factors that inactivated AIFIA or that suppressed or induced the release of AIFIA from monocytes. Further studies were done to corroborate this finding. In two separate experi-

B

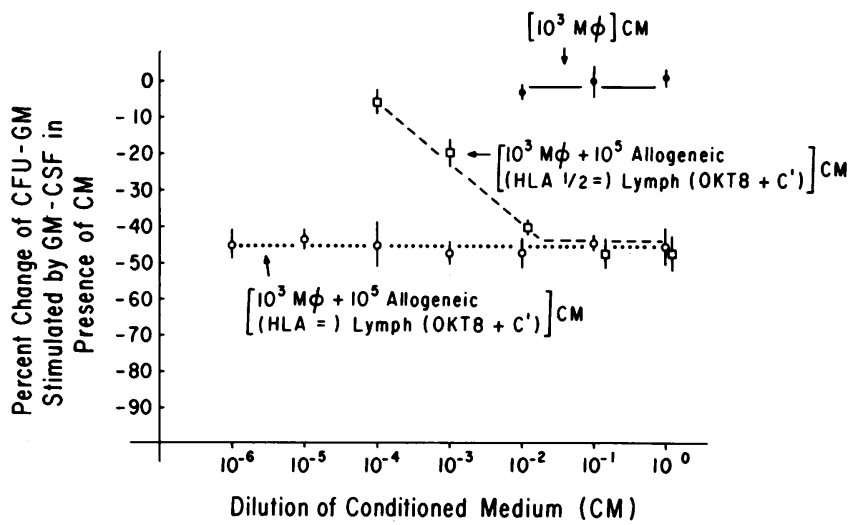

(A) Suppression of AIFIA release from $10^{5}$ monocytes $/ \mathrm{ml}$ by $\mathrm{OKT} 8^{+}$. enriched lymphocytes (pretreated to remove $\mathrm{OKT} 4^{+}$cells); $(B)$ Induction of AIFIA release from $10^{3}$ monocytes $/ \mathrm{ml}$ by OKT $4^{+}$-enriched lymphocytes (pretreated to remove $\mathrm{OKT} 8^{+}$cells). M $\phi$, monocyte. 
A

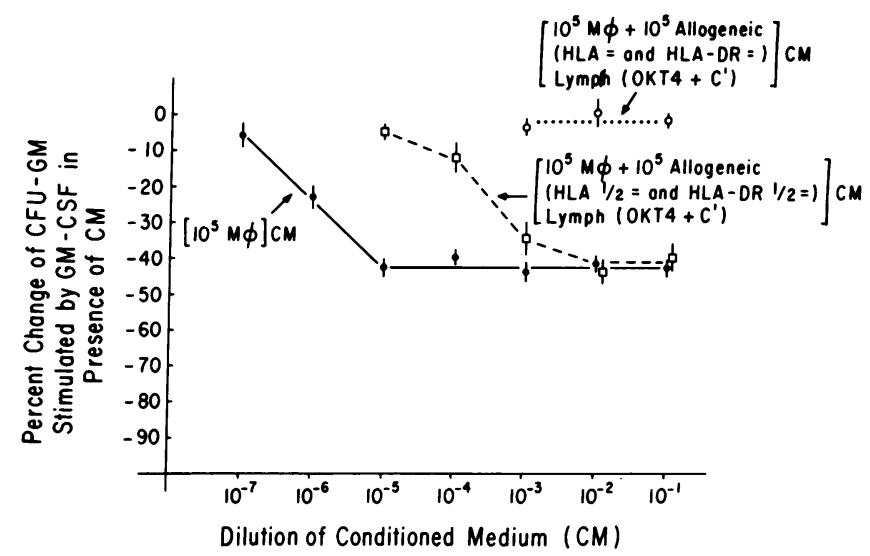

Figure 9. Unrelated donors. Release of AIFIA from human monocytes is modulated fully by allogeneic lymphocytes from HLA-identical $(H L A=)$ and by HLA-DR identical (HLA-DR $=$ ) unrelated donors and partially by allogeneic lymphocytes from HLA haploidentical (HLA 1/2=) and HLA-DR-haploidentical (HLA-DR 1/2=) unrelated
B

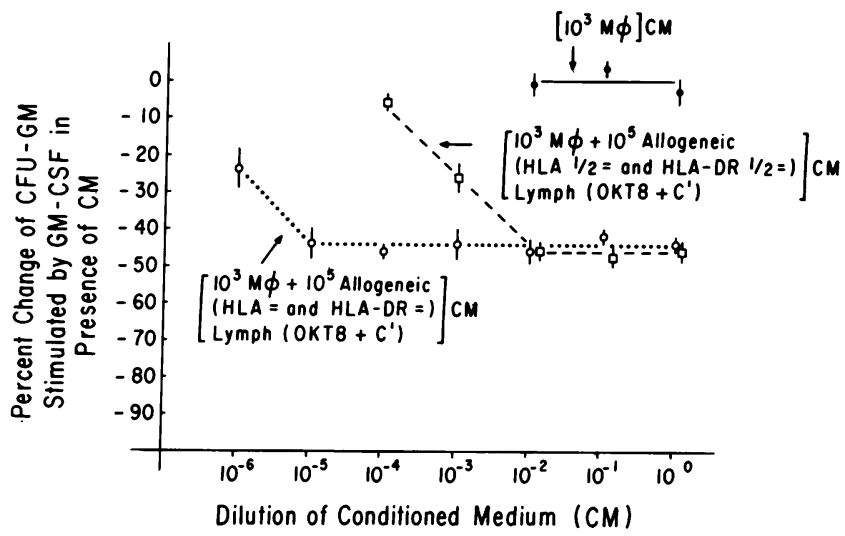

donors. (A) Suppression of AIFIA release from $10^{5}$ monocytes $/ \mathrm{ml}$ by $\mathrm{OKT} 8^{+}$-enriched lymphocytes (pretreated to remove $\mathrm{OKT} 4^{+}$cells). $(B)$ Induction of AIFIA release from $10^{3}$ monocytes $/ \mathrm{ml}$ by OKT4 ${ }^{+}$enriched lymphocytes (pretreated to remove $\mathrm{OKT}^{+}$cells). $\mathrm{M} \phi$, monocyte.

HLA-identical, unrelated combinations (HLA=):

(GK:RB)

GK and RB A1, CW7, B8, DR3

Al, Cw7, B8, DR3

HLA-DR-identical, unrelated combinations (HLA-DR=):

(MZ:LR; MZ:RM; LR:RM)

\begin{tabular}{ll} 
MZ & Aw24, Cw2, B14, DR1 \\
\cline { 2 - 2 } LR & Aw24, C-, B14, DR1 \\
& Aw23, C-, B14, DR1 \\
\hline R28, C-, B14, DR1 & A2, Cw5, Bw44, DR1 \\
\hline A2, Cw4, Bw35, DR1
\end{tabular}

HLA-haploidentical, unrelated combinations (HLA $1 / 2=$ ):

RD

A1, Cw7, B8, DR3

(GK:RD; RB:RD)

A2, C-, B12, DR7

HLA-DR-haploidentical, unrelated combinations (HLA-DR 1/2=):

(MZ:NF; LR:NF; RM:NF)

NF

A28, Cw8, B14, DR1

A26, C-, Bw41, DR3 ments, preincubating $10^{-9} \mathrm{M}$ purified acidic isoferritins or conditioned medium from $10^{5}$ monocytes $/ \mathrm{ml}$ with $25 \% \mathrm{vol} / \mathrm{vol}$ of medium conditioned with $10^{3}$ monocytes and $10^{5}$ HLA-nonidentical allogeneic OKT4 ${ }^{+}$-enriched lymphocytes, which itself did not have AIFIA, did not inactivate the inhibitory activity of the purified acidic isoferritins or the monocyte conditioned medium (data not shown). Moreover, in two other experiments, conditioning medium with $10^{5}$ monocytes $/ \mathrm{ml}$ in the presence of $20 \%$ ( $\mathrm{vol} / \mathrm{vol}$ ) of medium conditioned by $10^{3}$ monocytes plus $10^{5}$ HLA-nonidentical allogeneic OKT4 ${ }^{+}$-enriched lymphocytes had no influence on the amount of inhibitory activity released by the $10^{5}$ monocytes (data not shown). This substantiated the 

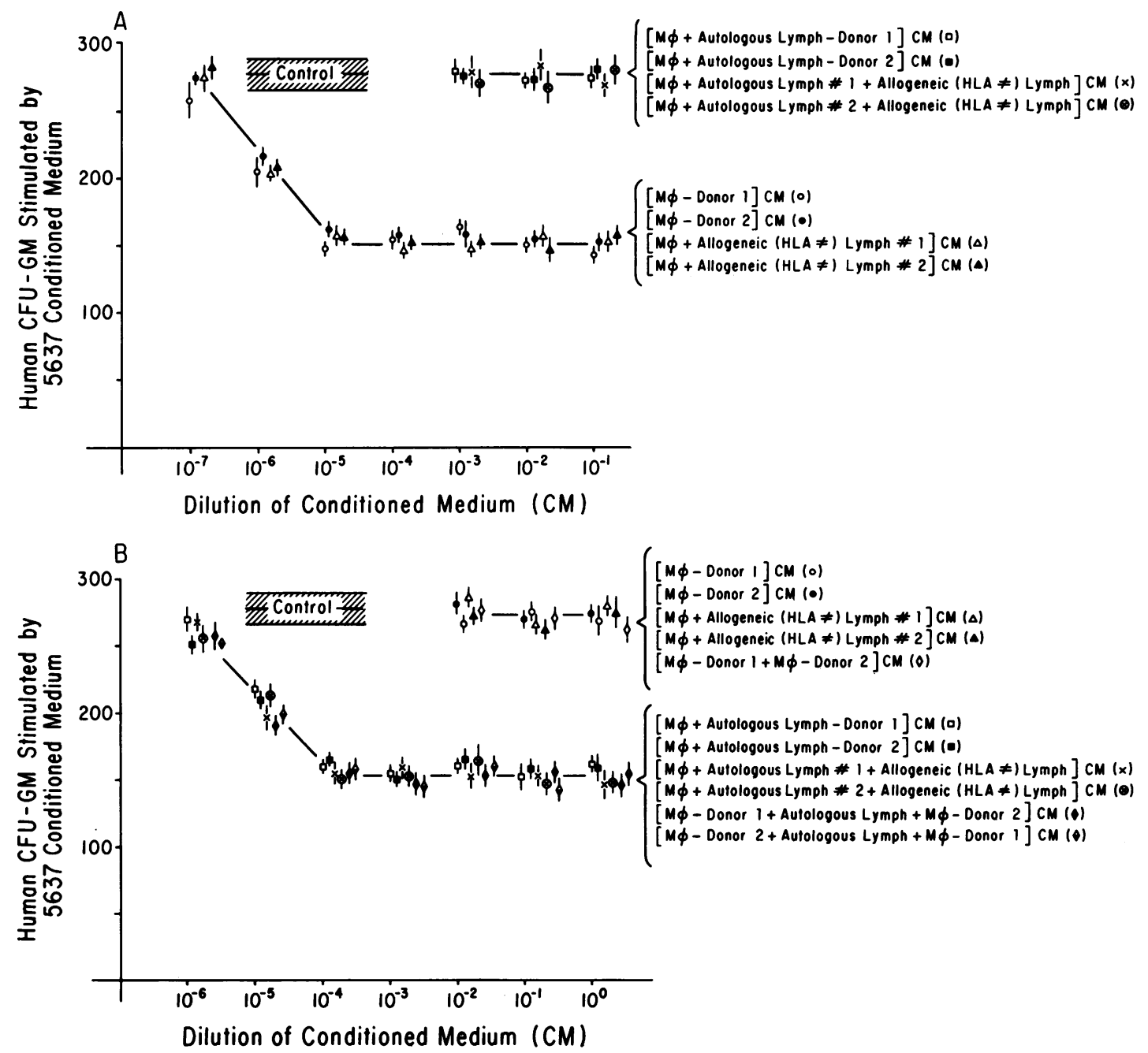

Figure 10. Allogeneic cell interactions do not block the autologous lymphocyte suppression $(A)$ or induction $(B)$ of AIFIA release from human monocytes. In $A$, medium was conditioned by $10^{5}$ monocytes $\pm 10^{5}$ autologous $0 K T 8^{+}$-enriched lymphocytes $\left(\mathrm{OKT} 4+\mathrm{C}^{\prime}\right) \pm 10^{5}$ HLA nonidentical allogeneic OKT $8^{+}$-enriched lymphocytes (OKT4

$\left.+C^{\prime}\right)$. In $B$, medium was conditioned with $10^{3}$ monocytes $\pm 10^{5}$ autologous OKT4 ${ }^{+}$-enriched lymphocytes $\left(O K T 8+C^{\prime}\right) \pm 10^{5}$ HLA-nonidentical OKT4 $4^{+}$-enriched lymphocytes $\left(\mathrm{OKT} 8+\mathrm{C}^{\prime}\right)$. $\mathrm{M} \phi$, monocyte.

information in Fig. 10 which suggested that allogeneic cell interactions did not release inactivators of AIFIA or inhibitors of the release of AIFIA

The relationship between induction and suppression of AIFIA release from monocytes by $\mathrm{T}$ lymphocytes was analyzed in the context of HLA-DR identity with or without positive reactivity in mixed lymphocyte culture reaction. The results obtained in the lymphocyte-monocyte combinations from HLAidentical sibling combinations and from the unrelated combination GK/RB which were MLC nonreactive were identical to the results obtained in cell combinations from the MLC positive combinations MZ/LR, MZ/RM, and LR/RM. The modulation

of AIFIA release from monocytes was as potent with the HLA genotypically identical sibling cell mixtures as with the HLAidentical unrelated, and HLA-DR identical, weakly MLC-positive cell mixtures.

The partial suppression or induction of AIFIA release obtained with lymphocyte-monocyte cell mixtures from donors who were HLA haploidentical or HLA-DR haploidentical was obtained independently of whether the lymphocytes originated from the MLC incompatible responder cell (i.e., cell combi-

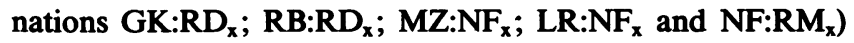
or from MLC-compatible combinations (i.e., $\mathbf{R D : G _ { x }} ; \mathbf{R D :} \mathbf{R B}_{\mathbf{x}}$; $N F: M Z_{x} ; N F: L_{x} ;$ and NF: $M_{x}$ ). These data indicated that 
compatibility for HLA-DR determinants between the lymphocytes and the monocytes was essential for the cell-cell interactions involved in the release of AIFIA, while the MLC-activating determinants themselves (i.e., HLA-D) did not seem to play a role in these interactions.

\section{Discussion}

This is, we believe, the first report of genetic restriction at the level of HLA-DR for T lymphocyte subset modulation of the release from monocytes of a soluble factor that is involved in the regulation of myelopoiesis, at least in vitro. Others have shown a requirement for I-A homology between murine lymphocytes and monocytes in the production of procoagulant activity (44). Monocyte-macrophage-derived acidic isoferritins suppress colony formation in vitro at the level of progenitor cells committed to multilineages (CFU-GEMM), the erythroid lineage (BFU-E), and the granulocyte-macrophage pathway (CFU-GM) (7-12). These studies demonstrate the specificity of the modulation of the release of AIFIA with regards to HLADR antigenic determinants.

AIFIA appears to involve the subpopulation of monocytes bearing HLA-DR determinants. This finding was suggested by negative selection experiments using anti-HLA-DR in a complement-dependent cytotoxicity test to remove HLA-DR ${ }^{+}$ monocytes. The possibilities exist that AIFIA may derive from a subset of monocytes with a high HLA-DR antigen density or that the release of AIFIA requires the cooperative action of high density HLA-DR ${ }^{+}$monocytes with lower density HLA-DR ${ }^{+}$or with HLA-DR ${ }^{-}$monocytes. Of importance in this regard is that while monocytes do not require $T$ lymphocytes to release AIFIA, subsets of $T$ lymphocytes can modulate the release of AIFIA from monocytes. The $T$ lymphocytes that are involved in this modulation are also HLA-DR ${ }^{+}$, but the percentage of $\mathrm{T}$ lymphocytes and especially $\mathrm{T}$ lymphocyte subsets that are HLA$\mathrm{DR}^{+}$under nonactivated conditions is small. Thus, HLA-DR ${ }^{+}$ $T$ lymphocytes may be acting as amplifier cells for HLA-DR ${ }^{-}$ $T$ lymphocytes. A precedent for $\mathrm{T}^{+}{ }^{+} \mathrm{HLA}-\mathrm{DR}^{+}$lymphocyte amplifier cells has been established by others (45).

The mechanism of action of the suppression of AIFIA release from monocytes by an $\mathrm{OKT}^{+} \mathrm{T}$ cell population and the enhancement and induction of release of AIFIA from monocytes by an $\mathrm{OKT}^{+} \mathrm{T}$ cell population is not yet clear, but may involve the release of soluble factors from the $T$ lymphocyte subsets and the monocytes. That the modulation of AIFIA release from monocytes can be blocked by pulsing either the lymphocytes or the monocytes with anti-HLA-DR, in the absence of $\mathrm{C}^{\prime}$, before culturing the separated cell populations together, suggests the possibility of two-way communication between the lymphocytes and monocytes. We have been able to condition culture medium with soluble factors from $\mathrm{T}$ lymphocyte subsets that can suppress or induce AIFIA release from monocytes (unpublished observations). However, these factors are not released if all monocytes are removed from the lymphocyte preparations by combinations of procedures including adherence to plastic, phagocytosis, and complement-dependent elimination of cells with monoclonal antibodies to surface determinants on monocytes. A small percentage of monocytes $(>2 \%)$ is needed for the release of the cell-free soluble factors from the T-cell subsets (H. E. Broxmeyer, E. Platzer, and B. Dupont, unpublished observations).

HLA-DR (Ia-like) antigenic determinants have been implicated previously in the regulations of myelopoiesis at the level of factor-cell interactions for lactoferrin (25-27), transferrin (26, $27,46)$, AIFIA $(7-10,26,27)$ and their respective specific target cell populations. Lactoferrin acts on an HLA-DR ${ }^{+}$population of human monocytes and on an $\mathrm{Ia}^{+}$population of mouse macrophages to limit the release of GM-CSF. Transferrin acts on an $\mathrm{HLA}-\mathrm{DR}^{+}$population of $\mathrm{T}$ lymphocytes to limit the mitogenactivated release of GM-CSF, and AIFIA acts on an HLA-DR ${ }^{+}$ population of cycling CFU-GEMM, BFU-E, and CFU-GM, and on an $\mathrm{Ia}^{+}$population of cycling mouse CFU-GM to decrease colony formation. HLA-DR antigenic determinants have also been implicated in cell-cell regulatory interactions in vitro for $T$ cells and BFU-E (47), and genetic restriction has been observed at the level of HLA-DR for a suppressor HLA-DR ${ }^{+} T$ cell action on BFU-E under normal conditions (48) and also on genetic restriction of $\mathrm{T}$ cell suppression of BFU-E during erythrocyte aplasia in the context of HLA (49). In these communications (47-49), it is possible that the $T$ cell-BFU-E interactions are mediated via other cells and possibly via AIFIA and/or other soluble factors.

Our studies of HLA-DR restriction of AIFIA release from monocytes have involved cell donors who were typed also for the HLA-DR-related alloantigens MB and MT (50-52). Since the HLA-DR-identical and HLA-DR-haploidentical unrelated donors included in this study were compatible also for the MB and/or MT determinant, we cannot at present evaluate the relative contributions of these different HLA-DR region determinants in these cell interactions. Our data demonstrate, however, that the MLC-activating determinants (i.e., HLA-D) are not involved directly in this effect.

$T$ cell modulation of AIFIA release from monocytes may be a means of maintaining steady state levels of AIFIA. It remains to be determined if these interactions are important physiologically and if aberrant $\mathrm{T}$ lymphocyte subset modulation of AIFIA release from monocytes is involved in the increased levels of cell-derived AIFIA noted during leukemia (3-6). Increased levels of AIFIA might relate to imbalances in such modulatory effects via quantitative or qualitative abnormalities in lymphocyte subsets or in their relative ratios to one another. It may also involve decreased or increased sensitivity of monocytes to the lymphocyte subsets and the absence or relative density distribution of HLA-DR antigens on the effector or responding cell populations. These phenomenon are now capable of being analyzed in the context of leukemia. 


\section{Acknowledgments}

This work was supported by grants CA 23528 (36740), CA 36740-01, CA 22507, CA 08748 from the National Cancer Institute, U. S. Public Health Service; grant PL-1031101 from the Deutsche Forschungsgemeinschaft to Dr. Platzer; the Regenstrief Foundation, and the Gar Reichman Foundation.

\section{References}

1. Broxmeyer, H. E. 1982. Hematopoietic stem cells. In The Human Bone Marrow. S. Trubowitz and S. Davis, editors. CRC Press, Boca Raton, FL. 1:77-123.

2. Broxmeyer, H. E. 1982. Granulopoiesis. In The Human Bone Marrow. S. Trubowitz and S. Davis, editors. CRC Press, Boca Raton, FL. 1:145-208.

3. Broxmeyer, H. E., N. Jacobsen, J. Kurland, N. Mendelsohn, and M. A. S. Moore. 1978. In vitro suppression of normal and granulocyte stem cells by inhibitory activity derived from leukemia cells. $J$. Natl. Cancer Inst. 60:497-511.

4. Broxmeyer, H. E., E. Grossbard, N. Jacobsen, and M. A. S. Moore. 1978. Evidence for a proliferative advantage of human leukemia colony forming cells (CFU-C) in vitro. J. Natl. Cancer. Inst. 60:513-521.

5. Broxmeyer, H. E., P. Ralph, V. B. Margolis, I. Naksinz, P. Meyers, N. Kapoor, and M. A. S. Moore. 1979. Characteristics of bone marrow and blood cells in human leukemia that produce inhibitory activity (LIA). Leukemia Res. 3:193-203.

6. Broxmeyer, H. E., E. Grossbard, N. Jacobsen, and M. A. S. Moore. 1979. Persistence of leukemia inhibitory activity during remission of acute leukemia. N. Engl. J. Med. 301:346-351.

7. Broxmeyer, H. E. 1982. Relationship of cell cycle expression of Ia-like antigenic determinants on normal and leukemia human granulocyte-macrophage progenitor cells to regulation in vitro by acidic isoferritins. J. Clin. Invest. 69:632-642.

8. Broxmeyer, H. E. 1982. Association of the sensitivity of mouse granulocyte-macrophage progenitor cells to inhibition by acidic isoferritins with expression of Ia antigens for I-A and I-E/C subregions during DNA synthesis. J. Immunol. 129:1002-1007.

9. Pelus, L. M. 1982. Association between colony forming unitsgranulocyte macrophage expression of Ia-like (HLA-DR) antigens and control of granulocyte and macrophage production. A new role for prostaglandin E. J. Clin. Invest. 70:568-578.

10. Lu, L., H. E. Broxmeyer, P. A. Meyers, M. A. S. Moore, and H. T. Thaler. 1983. Association of cell cycle expression of Ia-like antigenic determinants on normal human multipotential (CFU-GEMM) and erythroid (BFU-E) progenitor cells with regulation in vitro by acidic isoferritins. Blood. 61:250-256.

11. Broxmeyer, H. E., J. Bognacki, M. H. Dorner, and M. DeSousa 1981. Identification of leukemia associated inhibitory activity as acidic isoferritins. A regulatory role for acidic isoferritins in the production of granulocytes and macrophages. J. Exp. Med. 153:1426-1444.

12. Broxmeyer, H. E., J. Bognacki, P. Ralph, M. H. Dorner, L. Lu, and H. Castro-Malaspina. 1982. Monocyte-macrophage derived acidic isoferritins: Normal feedback regulators of granulocyte-macrophage progenitor cells in vitro. Blood. 60:595-607.

13. Taetle, R. 1981. Acidic isoferritins (leukemia associated inhibitory activity) fail to inhibit blast proliferation in acute myelogenous leukemia. Blood. 58:653-657.
14. Broxmeyer, H. E., P. Ralph, S. Gilbertson, and V. B. Margolis. 1980. Induction of leukemia-associated inhibitory activity and bone marrow granulocyte-macrophage progenitor cell alterations during infection with Abelson virus. Cancer Res. 40:3928-3933.

15. Marcelletti, J., and P. Furmanski. 1980. A murine model for the study of leukemia associated inhibitory activity. Blood. 56:134-137.

16. Johnson, C. S., J. Marcelletti, C. Longley, and P. Furmanski. 1982. Inhibition of normal erythropoiesis in mice with Friend virus induced erythroleukemia. Exp. Hematol. 10:743-753.

17. Unanue, E. R. 1980 . Cooperation between mononuclear phagocytes and lymphocytes in immunity. N. Engl. J. Med. 303:977-985.

18. Benacerraf, B. 1981. Cellular interactions. In The Role of the Major Histocompatibility Complex in Immunobiology. M. E. Dorf, editor. Garland STPM Press, New York. 255-269.

19. Verma, D. S., G. Spitzer, A. R. Zander, R. Fisher, K. B. McCredie, and K. A. Dicke. 1979. T-lymphocyte and monocyte-macrophage interaction in colony stimulating activity elaboration in man. Blood. 54:1376-1383.

20. Bagby, G. C., Jr., V. D. Rigas, R. M. Bennett, A. A. Vandenbark, and H. S. Garewal. 1981. Interaction of lactoferrin, monocytes, and T lymphocyte subsets in the regulation of steady-state granulopoiesis in vitro. J. Clin. Invest. 68:56-63.

21. Schreier, M. H., and N. H. Iscove. 1980. Haematopoietic growth factors are released in cultures of $\mathrm{H}-2$ restricted helper T-cells, accessory cells and specific antigen. Nature (Lond.). 287:226-230.

22. Winchester, R. J., and H. G. Kunkel. 1979. The human Ia system. Adv. Immunol. 28:221-292.

23. Winchester, R. J., G. D. Ross, C. I. Jarowski, C. Y. Wang, J. Halper, and H. E. Broxmeyer. 1977. Expression of Ia-like antigen molecules on human granulocytes during early phases of differentiation. Proc. Natl. Acad. Sci. USA. 74:4012-4016.

24. Winchester, R. J., P. A. Meyers, H. E. Broxmeyer, C. Y. Wang, M. A. S. Moore, and H. E. Kunkel. 1978. Inhibition of human erythropoietic colony formation in culture by treatment with Ia antisera. $J$. Exp. Med. 148:613-618.

25. Broxmeyer, H. E. 1979. Lactoferrin acts on Ia-like antigen positive subpopulations of human monocytes to inhibit production of colony stimulatory activity in vitro. J. Clin. Invest. 64:1717-1720.

26. Broxmeyer, H. E., P. Gentile, J. Bognacki, and P. Ralph. 1983. Lactoferrin, transferrin and acidic isoferritins. Regulatory molecules with potential therapeutic value in leukemia. Blood Cells. 9:83-105.

27. Broxmeyer, H. E. 1982. The association between Ia-antigens and regulation of myelopoiesis in vitro by iron-binding proteins. In Advances in Comparative Leukemia. 1981. D. S. Yohn and J. R. Blakeslee, editors. Elsevier-North Holland, New York. 81-86.

28. Yung, Y. P., and G. Cudkowicz. 1978. Suppression of cytotoxic T-lymphocytes by carrageenan-activated macrophage-like cells. J. Immunol. 121:1990-1997.

29. Hirano, T., T. Kuritani, T. Kishimoto, and Y. Yamamura. 1977. In vitro immune responses of human peripheral lymphocytes. I. The mechanism(s) involved in T-cell helper functions in the pokeweed mitogen-induced differentiation and proliferation of B-cells. J. Immunol. 119:1235-1241.

30. Kung, P. C., G. Goldstein, E. L. Reinherz, and S. F. Schlossman. 1979. Monoclonal antibodies defining distinctive human T-cell surface antigens. Science (Wash. DC). 206:347-349.

31. Royston, I., J. A. Majda, S. M. Baird, B. L. Meserve, and J. C. Griffiths. 1980. Human T cell antigens defined by monoclonal antibodies. The 65,000 dalton antigen of T-cells (T65) is also found on chronic 
lymphocytic leukemia cells bearing surface immunoglobulin. J. Immunol. 125:725-731.

32. Reinherz, E. L., P. C. Kung, G. Goldstein, and S. F. Schlossman. 1979. Separation of functional subsets of human T-cells by a monoclonal antibody. Proc. Natl. Acad. Sci. USA. 76:4061-4065.

33. Reinherz, E. L., P. C. Kung, G. Goldstein, and S. F. Schlossman 1980. A monoclonal antibody reactive with the human cytotoxic/sup pressor $\mathrm{T}$ cell subset previously defined by a heteroantiserum termed $\mathrm{TH}_{2}$. J. Immunol. 124:1301-1307.

34. Sutherland, R., D. Delia, G. Schneider, R. Newman, J. Kemshead, and M. Greaves. 1981. Ubiquitous cell-surface glycoprotein on tumor cells is proliferation associated receptor for transferrin. Proc. Natl. Acad. Sci. USA. 78:4515-4519.

35. Verbi, W., M. F. Greaves, C. Schneider, K. Koubek, G. Janossy, H. Stein, P. C. Kung, and G. Goldstein. 1982. Monoclonal antibodies OKT11 and OKT11a have pan-T reactivity and block erythrocyte "receptors." Eur. J. Immunol. 12:81-86.

36. Hansen, J. A., P. J. Martin, and R. C. Nowinski. 1980. Monoclonal antibodies identifying a novel T-cell antigen and Ia antigens of human lymphocytes. Immunogenetics. 10:247-260.

37. Springer, T., G. Galfre, D. S. Secher, and C. Milstein. 1979. Mac-1: a macrophage differentiation antigen identified by monoclonal antibody. Eur. J. Immunol. 9:301-306.

38. Wysocki, L. J., and V. L. Sato. 1978. "Panning" for lymphocytes: a method for cell selection. Proc. Natl. Acad. Sci. USA. 75:2844-2848.

39. Koski, I. R., D. G. Poplack, and R. M. Blaese. 1976. A nonspecific esterase method for the identification of monocytes and macrophages. In In Vitro Methods in Cell Mediated and Tumor Immunity. B. R. Bloom and J. R. David, editors. Academic Press, Inc., New York. 359-362.

40. DiPersio, J. F., J. K. Brennan, M. A. Lichtman, C. N. Abboud, and F. H. Kirkpatrick. 1980. The fractionation, characterization, and subcellular localization of colony stimulating activities released by the human monocyte-like cell line GCT. Blood. 56:717-727.

41. Svet-Moldavsky, G. J., S. N. Zinzar, I. A. Svet-Moldavskaya, P. E. Mann, J. F. Holland, J. Fogh, Z. Arlin, and B. D. Clarkson. 1980. CSF-producing human tumor cell lines. Lack of CSF activity of human stromal bone marrow fibroblasts. Exp. Hematol. 8(Suppl. 7):76.
42. Broxmeyer, H. E. 1982. Acidic isoferritins and E-type prostaglandins in sources of colony stimulatory factors mask detection of cycling granulocyte-macrophage progenitor cells. Blood. 60:1042-1045.

43. Dupont, B., J. A. Hansen, and E. J. Yunis. 1976. Human mixed lymphocyte culture reaction: genetics, specificity and biological implications. Adv. Immunol. 23:107-202.

44. Levy, G. A., and T. S. Edgington. 1982. The major histocompatibility complex requirement for cellular collaboration in the murine lymphoid procoagulant response stimulated by bacterial lipopolysaccharide. J. Immunol. 128:1284-1288.

45. Reinherz, E. L., C. Morimoto, A. C. Penta, and S. F. Schlossman. 1981. Subpopulations of the $\mathrm{T}^{+}$inducer $\mathrm{T}$-cell subsets in man: evidence for an amplifier population preferentially expressing Ia antigen upon activation. J. Immunol. 126:67-70.

46. Broxmeyer, H. E., L. Lu, and J. Bognacki. 1983. Transferrin, derived from an OKT8-positive subpopulation of T-lymphocytes, suppresses the production of granulocyte-macrophage colony stimulatory factors from mitogen activated T-lymphocytes. Blood. 62:37-50.

47. Torok-Storb, B., P. J. Martin, and J. A. Hansen. 1981. Regulation of in vitro erythropoiesis by normal $\mathrm{T}$ cells: evidence for two T-cell subsets with opposing function. Blood. 58:171-174.

48. Torok-Storb, B., and J. A. Hansen. 1982. Modulation of in vitro BFU-E growth by normal Ia-positive T cells is restricted by HLA-DR. Nature (Lond.). 298:473-474.

49. Lipton, J. M., L. M. Nadler, G. P. Canellos, M. Kudisch, C. S. Reiss, and D. G. Nathan. 1983. Evidence for genetic restriction in the suppression in erythropoeisis by $\mathrm{T}$ lymphocytes in man. J. Clin. Invest. 72:694-706.

50. Tosi, R., N. Tanigaki, D. Centis, G. Battista, B. Ferrara, and D. Pressman. 1978. Immunological dissection of human Ia molecules. $J$. Exp. Med. 148:1592-1611.

51. Duquesnoy, R. J., M. Marrari, and K. Annen. 1979. Identification of an HLA-DR associated system of B-cell alloantigens. Transplant Proc. 11:1757-1760.

52. Park, M. S., P. I. Terasaki, S. Nakata, and D. Aoki. 1980. Supertypic DR groups MT1, MT2 and MT3. In Histocompatibility Testing 1980. P. I. Terasaki, editor. UCLA Tissue Typing Laboratory, Los Angeles. 854-860. 